\title{
The Influence of Different Lay-Up Parameters on the Fatigue Response of Carbon/Epoxy Laminates under Internal Multiaxial Stress States
}

\author{
Kalliopi-Artemi Kalteremidou *(D), Danny Van Hemelrijck and Lincy Pyl \\ Department of Mechanics of Materials and Constructions, Vrije Universiteit Brussel, Pleinlaan 2, \\ 1050 Brussels, Belgium; Danny.Van.Hemelrijck@vub.be (D.V.H.); Lincy.Pyl@vub.be (L.P.) \\ * Correspondence: Kalliopi-Artemi.Kalteremidou@vub.be
}

Citation: Kalteremidou, K.-A.; Van Hemelrijck, D.; Pyl, L. The Influence of Different Lay-Up Parameters on the Fatigue Response of Carbon/Epoxy Laminates under Internal Multiaxial Stress States. Materials 2021, 14, 7494. https:// doi.org/10.3390/ma14247494

Academic Editor: Andrea Bernasconi

Received: 3 November 2021

Accepted: 4 December 2021

Published: 7 December 2021

Publisher's Note: MDPI stays neutral with regard to jurisdictional claims in published maps and institutional affiliations.

Copyright: (c) 2021 by the authors. Licensee MDPI, Basel, Switzerland. This article is an open access article distributed under the terms and conditions of the Creative Commons Attribution (CC BY) license (https:/ / creativecommons.org/licenses/by/ $4.0 /)$.

\begin{abstract}
The inherent anisotropy of composites complicates their damage response. The influence of multiaxiality, particularly in carbon-based composites, is not thoroughly understood due to obstacles related to damage monitoring during loading. In this study, the response of different carbon/epoxy laminates under fatigue is examined through dedicated in situ microscopic observations. By varying the orientation of off-axis layers, the impact of multiaxiality on the mechanical and damage response is evaluated. Furthermore, balanced and unbalanced laminates are compared, considering the limited information for the latter. The influence of the number of off-axis layers is finally assessed leading to important conclusions about optimal fatigue response. The fatigue response is evaluated in all cases considering both the mechanical properties and the damage characteristics. Significant conclusions are drawn, especially for the benefits of unbalanced laminates and the impact of shear stresses, allowing for the utilization of the obtained data as important input for the establishment of reliable fatigue damage models.
\end{abstract}

Keywords: multiaxial fatigue; damage accumulation; fatigue crack growth; S-N curves; unbalanced laminates

\section{Introduction}

Understanding the behaviour of composite materials under multiaxial dynamic loads is essential in order to design high-performance materials and to develop physically based models suitable to predict the fatigue life and damage. A quite detailed review on the multiaxial fatigue investigation of composite materials was given by Quaresimin [1] According to this review, multiaxial studies on composites are still limited, and dedicated experimental campaigns have to be performed in order to understand in depth how different multiaxial conditions influence the fatigue damage accumulation. The majority of the fatigue experimental works in composites concern common unidirectional (UD) or cross-ply lay-ups in which nearly uniaxial stress states are developed and the multiaxiality is not taken into account. By contrast, in cases where multiaxiality is indeed considered, damage studies are limited either to damage initiation or to damage propagation; therefore, detailed damage sequences and their correlation with generic stress states are hardly reported [2]. Especially elaborate damage studies in Carbon Fibre Reinforced Polymers (CFRPs) when different multiaxial stress states occur are rarely found.

Indeed, a large experimental library can be found in the literature regarding fatigue testing of UD or cross-ply laminates, in which mainly uniaxial stress states are developed [3-11]. The damage response of $\left[45^{\circ} /-45^{\circ}\right]$ laminates during fatigue has been also investigated [12,13]. However, also in this type of angle-ply laminates, pure shear is developed in the individual plies. In all these cases where more straightforward uniaxial stress states are developed, the initiation and growth of matrix cracks and delaminations has been monitored in detail using different techniques, and the fatigue damage accumulation 
has been clearly identified [14-18]. It is commonly accepted that damage initiates in the form of matrix cracks which lead to interlaminar delaminations propagating and leading to final failure [19-21]. However, it is still not clear how more complex multiaxial stress states influence the fatigue damage initiation and the consequent damage accumulation.

As a matter of fact, experimental studies on the fatigue damage response of polymer composites under multiaxial stresses are rarely found. Flat laminates consisting of offaxis plies have been, for instance, examined in [22-24]. However, the fatigue response of the composites in the majority of these cases has been studied mainly in terms of S-N curves $[25,26]$ or stiffness degradation measurements, and detailed damage monitoring is not reported. Damage measurements in laminates under multiaxial loading are very limited in the literature. May et al. [27] examined, for instance, the matrix cracking initiation during fatigue in CFRP $\left[\left(0^{\circ}\right)_{2} /\left(90^{\circ}\right)_{4}\right]_{\mathrm{s}}$ and $\left[\left(0^{\circ}\right)_{2} /\left(60^{\circ}\right)_{4}\right]_{\mathrm{s}}$ laminates using X-rays and Acoustic Emission (AE). However, detailed damage monitoring throughout the total material life is not reported. Quaresimin et al. [28] compared the damage initiation and propagation in Glass Fibre Reinforced Polymer (GFRP) tubular and flat specimens when the same multiaxial stresses were developed. However, also in this case, only matrix cracking phenomena are reported and correlated with the developing multiaxial stresses. Moreover, their approach is restricted to GFRPs because of the transparency of the glass fibres, allowing for damage monitoring by fixing the proper lightning conditions [29-32]. Thus, the need to study the fatigue damage response of CFRP laminates under multiaxial stresses has been made clear through the lack of the existing literature in polymer composites.

Multiaxiality in composites can be applied in two ways: internally and externally. The internal multiaxiality in composites arises from their inherent anisotropy. This means that even under simple uniaxial loading of flat laminates, multiaxiality can be developed in off-axis plies, i.e., in plies where the fibres are not parallel to the loading direction. External multiaxiality can be applied using two loading systems: for instance, by performing combined tension/torsion tests in tubes [33-35] or by applying biaxial loading to cruciform specimens [36-38]. In general, when it comes to studying the fatigue behaviour of composites under multiaxial loads, it should not be necessary to distinguish between internal and external multiaxiality as far as the local stresses in the material remain identical [1]. Tubular specimens have been shown to be quite effective for multiaxial testing of composites, but some influence of the thickness-to-radius ratio on the fatigue life has been reported [39]. Moreover, even though the absence of free edges on tubes can guarantee that no interlaminar stresses are developed, it can also be considered as a significant disadvantage because damage monitoring is restricted. Regarding cruciform specimens, dedicated research has demonstrated that it is quite difficult to obtain an optimised geometry that can guarantee successful biaxial testing by localising the damage in the central part of the specimen. On the other hand, widely applied uniaxial testing of flat specimens gives the possibility to study the multiaxiality in composites just by altering the stacking sequence. Angle-ply laminates can be tested for this purpose, and by selecting the angle $\theta$ of off-axis layers, certain biaxial or multiaxial conditions can be established. The free edges of the flat specimens are sometimes considered a drawback due to the nucleation of high interlaminar stresses leading to delaminations. However, in the majority of real applications, flat laminates are used consisting of free edges. Thus, the knowledge of the impact of multiaxial stress conditions on the fatigue damage initiation and growth in such geometries is of great importance.

To that end, an extensive fatigue testing campaign is described in this work. The effect of multiaxiality is primarily investigated. Eight-ply laminates including off-axis layers with an orientation equal to $30^{\circ}$ or $60^{\circ}$ were tested to establish different multiaxial stress states and to examine the influence of shear on the fatigue behaviour. Furthermore, balanced laminates were compared with unbalanced lay-ups with the same off-axis layers. In a balanced laminate, for every $+\theta$ ply, another $-\theta$ ply of the same thickness and material exists. This is not the case for the unbalanced laminates used in this study, consisting only of $+\theta$ plies. A beneficial response of the unbalanced laminates was identified during a 
quasistatic study of the considered laminates in a previous work of the authors [40]. The potential of an improved fatigue response is therefore evaluated in the current study. The impact of the number of the off-axis layers is also examined by testing 12-ply laminates, including eight instead of four off-axis plies. Apart from these parameters, the impact of the fatigue stress level as well as the influence of the R-ratio were investigated.

The fatigue response was evaluated considering both the mechanical properties and the damage characteristics. Initially, $\mathrm{S}-\mathrm{N}_{\mathrm{f}}$ (stress-cycles to failure) data for the different types of laminates were established. Their residual strength was then obtained and correlated with the multiaxial stresses. The fatigue damage accumulation was afterward reported. Detailed damage monitoring was performed by attaching an optical microscope on the test bench and by scanning the edge of the specimen at different test intervals while keeping it loaded. The matrix cracking increase and the delamination growth during testing were precisely revealed in order to examine the impact of shear on the damage accumulation, as well as the response of the rarely studied unbalanced laminates. An effort was made to establish empirical rules for the prediction of damage accumulation based on matrix cracking density measurements when different stress components dominate in the off-axis layers. The stiffness degradation and the evolution of the Poisson's ratio were finally reported for the examined laminates as measured by using a Digital Image Correlation (DIC) system. Significant differences were observed, allowing for the utilisation of the obtained data as an important input for the establishment of reliable fatigue damage models.

\section{Materials and Methods}

\subsection{Selection of Material}

The material used in the present study is TR 360E250S pre-preg CFRP in the form of flat laminates, manufactured by Mitsubishi Chemical Corporation and Honda R\&D Co., Ltd. (Tokyo, Japan). The pre-preg consists of PYROFIL \#361 $130{ }^{\circ} \mathrm{C}$ curing-modified epoxy resin and PYROFIL TR 50S15L continuous PAN-based carbon fibres. The material was cured in an autoclave for $60 \mathrm{~min}$ at a temperature of $130^{\circ} \mathrm{C}$ and a pressure of $0.6 \mathrm{MPa}$. The mechanical properties of the CFRP composite material were obtained by standard tensile tests on $\left[0^{\circ}\right]_{4},\left[90^{\circ}\right]_{8}$ and $\left[45^{\circ} /-45^{\circ}\right]_{2 s}$ specimens with dimensions according to ASTM D3039 [41] and are summarised in Table 1 (with $\sigma_{11, \text { ult }}, \sigma_{22, \text { ult }}$ and $\tau_{12 \text {,ult }}$ representing the ultimate longitudinal, transverse and shear strengths, respectively; $E_{11}, E_{22}$ and $G_{12}$ the longitudinal, transverse and shear elastic moduli, respectively; and $v_{12}$ the Poisson's ratio, all calculated in the material coordinate system).

Table 1. Measured mechanical properties of the Carbon Fibre Reinforced Polymer (CFRP) material.

\begin{tabular}{ccc}
\hline Property & Value (Average and Standard Error) & Unit \\
\hline$\sigma_{11, \text { ult }}$ & $2272 \pm 89$ & $\mathrm{MPa}$ \\
\hline$\sigma_{22, \mathrm{ult}}$ & $53 \pm 2$ & $\mathrm{MPa}$ \\
\hline$\tau_{12, \mathrm{ult}}$ & $52 \pm 1$ & $\mathrm{MPa}$ \\
\hline $\mathrm{E}_{11}$ & $125.8 \pm 3.9$ & $\mathrm{GPa}$ \\
\hline $\mathrm{E}_{22}$ & $9.4 \pm 0.3$ & $\mathrm{GPa}$ \\
\hline $\mathrm{G}_{12}$ & $4.1 \pm 0.1$ & $\mathrm{GPa}$ \\
\hline$v_{12}$ & $0.335 \pm 0.014$ & - \\
\hline
\end{tabular}

As also mentioned in the introduction, the influence of three parameters is studied in this work, i.e., the occurrence of multiaxial stresses, the comparison between balanced and unbalanced lay-ups and the number of off-axis plies. For this reason, six angle-ply flat laminates were tested. Here, $\left[0^{\circ} / \theta\right]_{2 s}$ unbalanced laminates were initially chosen for two different $\theta$ values to account for dissimilar multiaxiality in the off-axis layers. The characteristic of this lay-up is that no negative counterpart of the angle $\theta$ exists in the 
laminate. Secondly, $\left[0^{\circ} / \theta / 0^{\circ} /-\theta\right]_{\mathrm{S}}$ balanced laminates with the same $\theta$ values were tested. Finally, $\left[0^{\circ} / \theta /-\theta\right]_{2 \mathrm{~s}}$ laminates were assessed to examine the influence of the number of off-axis layers on the mechanical response.

The off-axis angle values $\theta$ were chosen based on calculations using the Classical Laminate Theory (CLT). Considering that most failure criteria make use of stresses and strains in the material coordinate system, it was decided to choose the angle of the off-axis layers based on the biaxiality ratios $\lambda$, which express the relation between the normal and shear stresses in the principal directions [1], defined as:

$$
\left|\lambda_{1}\right|=\left|\frac{\sigma_{22}}{\sigma_{11}}\right|,\left|\lambda_{2}\right|=\left|\frac{\tau_{12}}{\sigma_{11}}\right|,\left|\lambda_{12}\right|=\left|\frac{\tau_{12}}{\sigma_{22}}\right|
$$

where $\sigma_{11}$ and $\sigma_{22}$ are the in-plane longitudinal and transverse stress components and $\tau_{12}$ is the in-plane shear stress in the material coordinate system. Special focus was given to the $\lambda_{12}$ biaxiality ratio, linking the in-plane transverse with the shear stress, to study the influence of their combination on the mechanical response. Based on calculations from the CLT, the evolution of the absolute values of the $\lambda$ ratios is plotted in Figure 1 versus the angle $\theta$ for all considered laminates. To obtain a different multiaxial condition, two angles were chosen based on Figure 1, namely $30^{\circ}$ and $60^{\circ}$. It can be seen from Figure $1 \mathrm{a}$ that in the $\left[0^{\circ} / \theta\right]_{2 s}$ lay-up the $\lambda_{12}$ ratio is equal to 2.02 for $\theta=30^{\circ}$, whereas in the $60^{\circ}$ layers, it equals 0.64 . These values depict that in the $\left[0^{\circ} / 30^{\circ}\right]_{2 \mathrm{~s}}$ laminates, the shear stresses $\tau_{12}$ are dominant in the off-axis plies, while the transverse stresses $\sigma_{22}$ represent the highest stress component in the $60^{\circ}$ layers of the $\left[0^{\circ} / 60^{\circ}\right]_{2 s}$ laminates. In both cases, the stress along the fibre direction $\sigma_{11}$ is much lower than the unidirectional strength of the material $\sigma_{11 \text {,ult }}$ in the off-axis layers, as depicted by looking at the $\lambda_{1}$ and $\lambda_{2}$ ratios in Figure 1a, showing that the $\sigma_{11}, \sigma_{22}$ and $\tau_{12}$ stresses are of the same order of magnitude. Moreover, the same boundary conditions apply for both cases, with the insertion of $0^{\circ}$ plies alternating the off-axis layers. This indicates that a direct comparison between the two laminates is allowed, letting the examination of the different matrix-dominated behaviour in the off-axis layers depend on either dominant shear or transverse stresses and not on fibre-related phenomena.

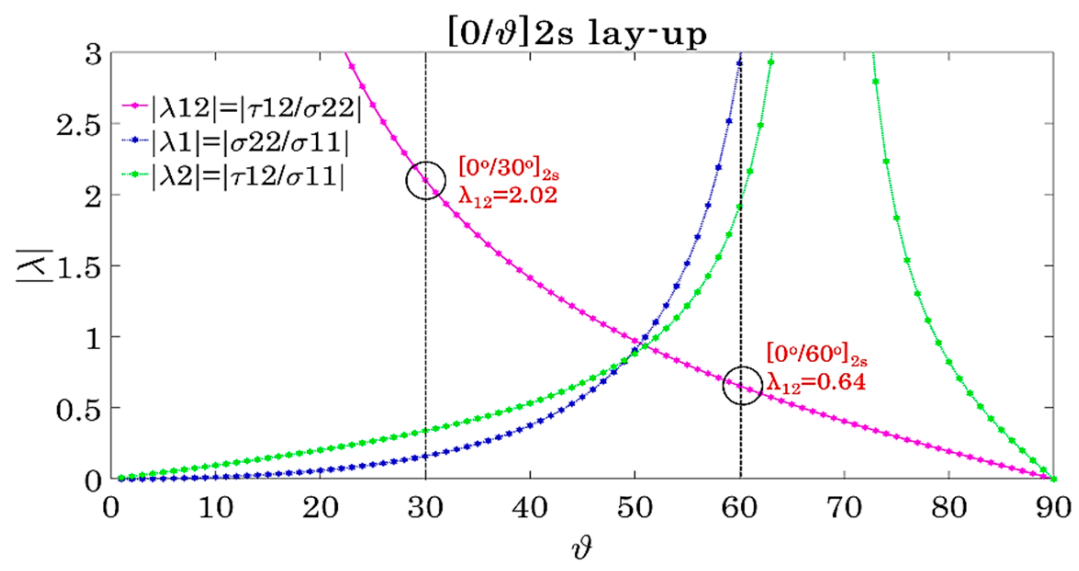

(a)

Figure 1. Cont. 


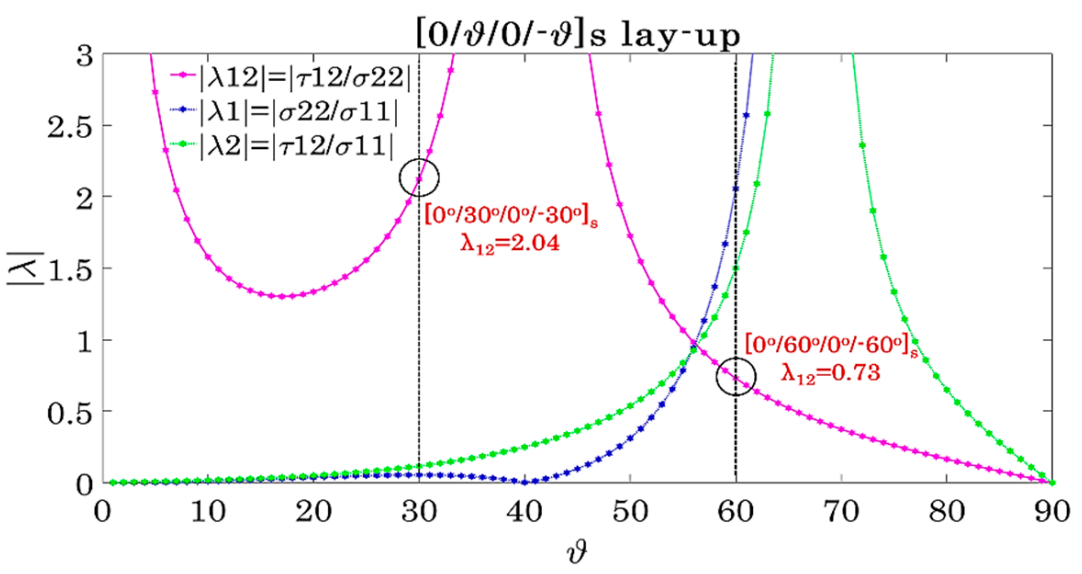

(b)

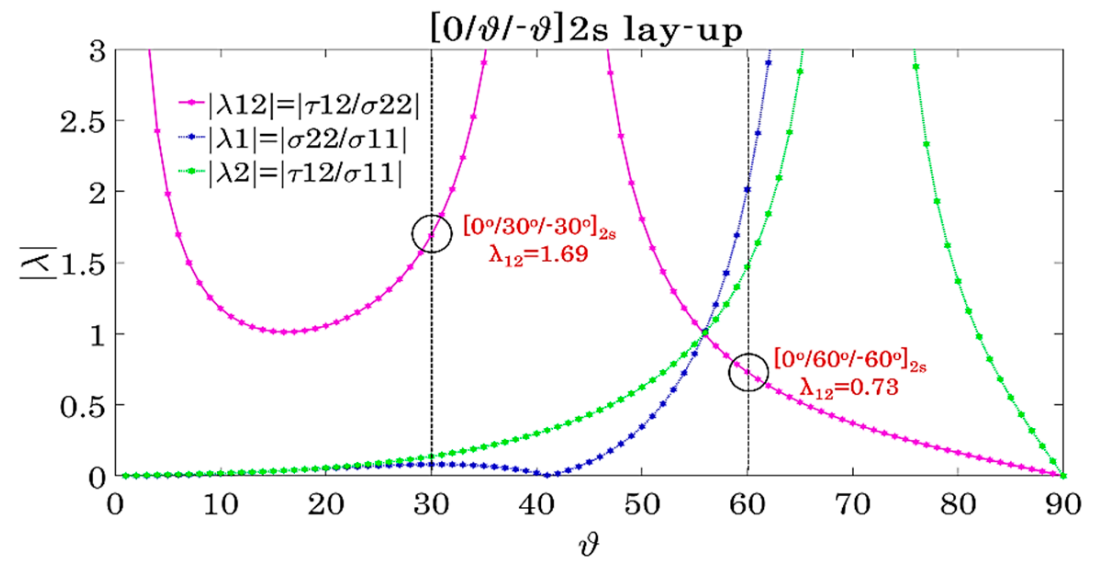

(c)

Figure 1. Absolute biaxiality ratios $\lambda$ in the off-axis layers of $(\mathbf{a})\left[0^{\circ} / \theta\right]_{2 \mathrm{~s}},(\mathbf{b})\left[0^{\circ} / \theta / 0^{\circ} /-\theta\right]_{\mathrm{s}}$ and (c) $\left[0^{\circ} / \theta /-\theta\right]_{2 \mathrm{~s}}$ laminates versus $\theta$.

In Figure $1 b$, the corresponding absolute biaxiality ratios for the balanced laminates are plotted. It can be calculated that $\lambda_{12}$ equals 2.04 in the $30^{\circ}$ plies of the $\left[0^{\circ} / 30^{\circ} / 0^{\circ} /-30^{\circ}\right]_{\mathrm{s}}$ laminates and 0.73 in the $60^{\circ}$ layers of the $\left[0^{\circ} / 60^{\circ} / 0^{\circ} /-60^{\circ}\right]_{s}$ laminates. Finally, to examine the influence of the relative number of the off-axis layers $\theta$ with respect to the number of $0^{\circ}$ layers, $\left[0^{\circ} / 30^{\circ} /-30^{\circ}\right]_{2 \mathrm{~s}}$ and $\left[0^{\circ} / 60^{\circ} /-60^{\circ}\right]_{2 \mathrm{~s}}$ laminates were tested, consisting of eight instead of four off-axis plies. In Figure $1 c$, the variation of the absolute biaxiality ratios for the thicker 12-ply $\left[0^{\circ} / \theta /-\theta\right]_{2 \mathrm{~s}}$ lay-up is plotted, with $\lambda_{12}$ equalling 1.69 in the $30^{\circ}$ plies of the $\left[0^{\circ} / 30^{\circ} /-30^{\circ}\right]_{2 s}$ laminates. This shows that by increasing the number of the off-axis plies, $\lambda_{12}$ decreases; thus, the shear influence has the tendency to decrease. However, the behaviour remains shear-dominated. This phenomenon diminishes by increasing $\theta$. In the $60^{\circ}$ off-axis layers of the $\left[0^{\circ} / 60^{\circ} /-60^{\circ}\right]_{2 s}$ laminates, $\lambda_{12}$ equals 0.73 , being similar to the 8-ply $\left[0^{\circ} / 60^{\circ}\right]_{2 s}$ and $\left[0^{\circ} / 60^{\circ} / 0^{\circ} /-60^{\circ}\right]_{s}$ laminates.

The dimensions of the tested specimens were defined based on [41]. All samples had a total length equal to $250 \mathrm{~mm}$ and a width of $25 \mathrm{~mm}$. The thickness of the 8-ply laminates was equal to $1.83 \mathrm{~mm}$ on average, whereas for the 12-ply laminates, it equalled $2.74 \mathrm{~mm}$ (Figure 2). All specimens were tabbed for a length of $50 \mathrm{~mm}$ on both sides using GFRP material in a $\left[0^{\circ} / 90^{\circ}\right]_{2 s}$ configuration to ensure failure within the gauge length. 

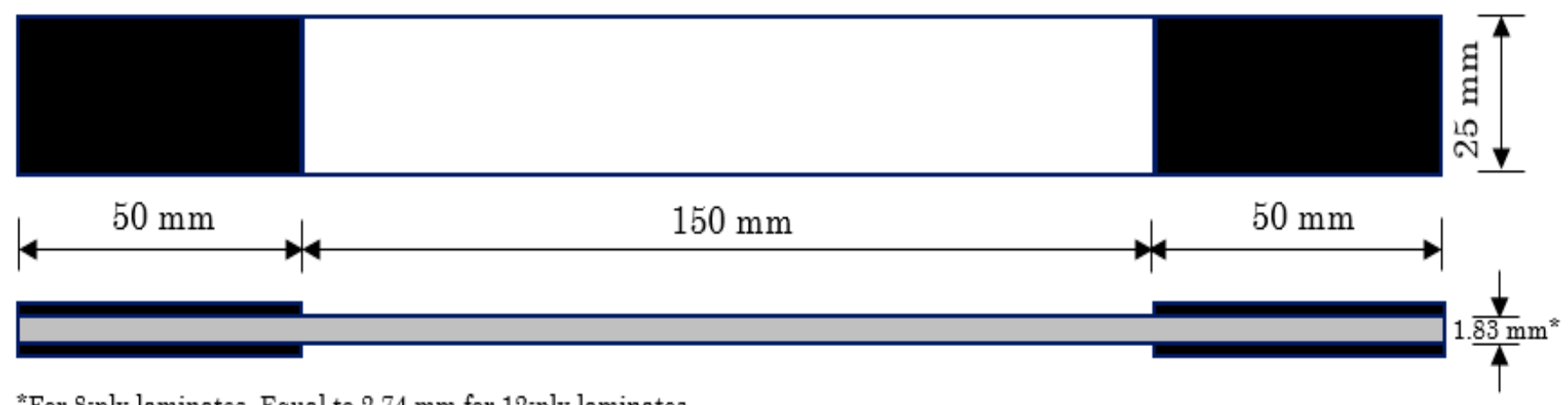

"For 8-ply laminates. Equal to $2.74 \mathrm{~mm}$ for 12 ply laminates.

Figure 2. Specimen dimensions.

\subsection{Experimental Details}

An MTS fatigue testing system with two servohydraulic grips, with a maximum load capacity of $100 \mathrm{kN}$, was used for the experimental campaign. Constant amplitude loadcontrolled fatigue tests at a frequency of $3 \mathrm{~Hz}$ were performed for all considered laminates. Initially, continuous fatigue loading was applied to all specimens until catastrophic failure occurred or until the fixed run-out value was reached. Three maximum fatigue stress levels $\sigma_{\max }$ were applied, corresponding to $70 \%, 80 \%$ and $90 \%$ of the respective ultimate strength $\sigma_{\text {ult }}$ for each laminate. $\Sigma_{\text {ult }}$ was obtained from initial static tests, and it was found to be equal to $1375,1318,1057,1213,967$ and $891 \mathrm{MPa}$ for the $\left[0^{\circ} / 30^{\circ}\right]_{2 \mathrm{~s}},\left[0^{\circ} / 60^{\circ}\right]_{2 \mathrm{~s}}$, $\left[0^{\circ} / 30^{\circ} / 0^{\circ} /-30^{\circ}\right]_{\mathrm{s}},\left[0^{\circ} / 60^{\circ} / 0^{\circ} /-60^{\circ}\right]_{\mathrm{s}},\left[0^{\circ} / 30^{\circ} /-30^{\circ}\right]_{2 \mathrm{~s}}$ and $\left[0^{\circ} / 60^{\circ} /-60^{\circ}\right]_{2 \mathrm{~s}}$ laminates, respectively [40]. One more stress level with $\sigma_{\max }$ equalling $60 \%$ of $\sigma_{\text {ult }}$ was applied for the continuous tests to verify the endurance limit of all laminates. Two R-ratios were considered, namely 0.1 and 0.5 . The run-out value was set to one million cycles, typical for fatigue studies in composites.

Based on the continuous tests and the total number of cycles to failure $\mathrm{N}_{\mathrm{f}}$ for each case, interrupted fatigue tests were then performed to assess the microscopic through-thickness damage evolution at certain fatigue intervals for the $70 \%, 80 \%$ and $90 \%$ test cases. For the specimens that reached the run-out value of one million cycles during the continuous tests, test interruptions were performed after 10, 50, 200, $10^{3}, 10^{4}, 10^{5}, 3 \times 10^{5}, 5 \times 10^{5}, 7.5 \times 10^{5}$ and $10^{6}$ cycles. The same initial intervals were applied to the rest of the specimens as well, but the frequency of microscopic monitoring was altered based on the obtained $\mathrm{N}_{\mathrm{f}}$ from the continuous tests for each case. The frequency of microscopic inspection is given in Table 2.

Table 2. Frequency of microscopic inspection for the fatigue tests.

\begin{tabular}{ccc}
\hline Fatigue Tests & \multicolumn{1}{c}{ Microscopic Inspection after $(\mathbf{x})$ Cycles } \\
\hline For $\mathrm{N}_{\mathrm{f}}=10^{6}$ cycles & $10,50,200,10^{3}, 10^{4}, 10^{5}, 3 \times 10^{5}, 5 \times 10^{5}, 7.5 \times 10^{5}, 10^{6}$ \\
\hline Condition & Cycle count & Microscopic inspection every (x) cycles \\
\hline If $\mathrm{N}_{\mathrm{f}}<10^{3}$ & 50 -failure & 50 \\
If $\mathrm{N}_{\mathrm{f}}<10^{4}$ & $10^{3}$-failure & $10^{3}$ \\
If $\mathrm{N}_{\mathrm{f}}<10^{5}$ & $10^{4}$-failure & $10^{4}$ \\
If $\mathrm{N}_{\mathrm{f}}<10^{6}$ & $5 \times 10^{4}$-failure & $5 \times 10^{4}$ \\
\hline
\end{tabular}

An optical microscope was used for in situ through-thickness monitoring of the fracture patterns during the interrupted tests. Specifically, each time a specific number of cycles during the fatigue tests was reached (according to Table 2), the tests were interrupted, and the specimens were kept under a load close to the maximum fatigue load applied at each case. By keeping the specimens tensioned, through-thickness damage observations on their free edge were performed along their gauge length. This was possible by attaching special bars on the test bench, which allowed the movement of the optical microscope along the length of the specimens (Figure 3). By scanning the total length of the specimens, 
the measurement of the matrix crack densities and the delamination lengths was possible using the corresponding measurement tools of the microscope's software. The advantage of this set-up is that load is still applied to the specimens during the observations; therefore, the occurring cracks are still open and visible, in contrast to the cases in which only postmonitoring is performed. The microscope used was an MZ125 stereomicroscope by Leica Microsystems with 8-100× magnification, attached to a Leica DFC 295 digital camera with a standard resolution of 3 MP. Prior to testing, the free edges of the samples were polished starting with fine $\mathrm{SiC}$ grit papers of $46 \mu \mathrm{m}$ particle size and going down to $5 \mu \mathrm{m}$. This eliminated weak areas at the free edges whilst allowing for recording sharp images. In order to confirm that the findings of the microscope along one edge of the specimens were not caused by an unbalanced load introduction, a Dino-Lite USB microscope with a 1.3 MP sensor and 20-230 $\times$ magnification was used for damage monitoring on both sides of the specimens, during all test intervals. Even if optimal focus is not achieved with this microscope, since it is not mounted on the test bench, the advantage is its flexibility as it can be used to scan the total length of the specimens.

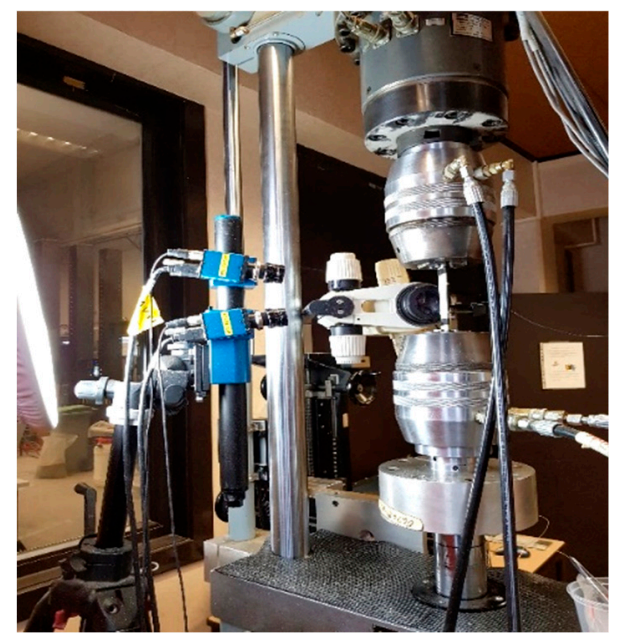

(a)

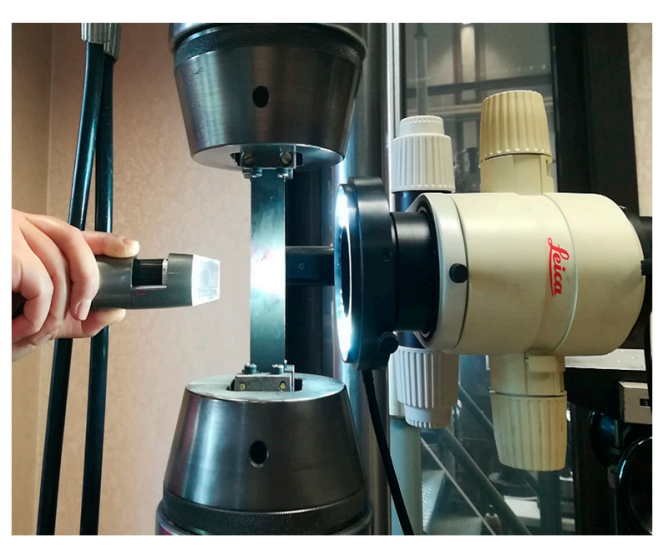

(b)

Figure 3. (a) Experimental set-up and (b) microscopes for damage monitoring.

A DIC system was also utilised during the fatigue tests for strain measurements. Two Charge Couple Device (CCD) cameras were mounted in front of the testing samples, and a random speckle pattern was applied to their front side. By triangulation between the two cameras, 3D displacement and strain measurements on their front surface could be provided. Two $23 \mathrm{~mm}$ lenses were used to capture the DIC images. A subset of 21 pixels by 21 pixels was used, and a step of 7 pixels was applied during the DIC analysis, performed with the VIC-3D software of Correlated Solutions. The features of the DIC system are shown in Table 3, including the obtained resolution and sensitivity. The DIC system was fixed to take one image during the application of the maximum and minimum load (peaks) to the sample at specific cycle points. The image acquisition frequency through the DIC system is shown in Table 4. Apart from the DIC system, an MTS extensometer with $50 \mathrm{~mm}$ gauge length and $5 \%$ measuring strain range was used for strain measurements on the opposite side of the specimens during all examined test cases. In Figure 3a, the experimental set-up is presented, showing the exact placement of the measuring systems. One indicative image of the applied microscopes on the MTS test bench is shown in Figure $3 \mathrm{~b}$. 
Table 3. Digital Image Correlation (DIC) system configuration.

\begin{tabular}{ccc}
\hline Parameter & Value & Unit \\
\hline Lenses & 23 & $\mathrm{~mm}$ \\
\hline Subset size & 21 & pixels \\
\hline Step size & 7 & pixels \\
\hline Resolution $(\mathrm{x} \times \mathrm{y})$ & $2085 \times 896$ & $\mathrm{pixels}$ \\
\hline Sensitivity & 0.028 & $\mathrm{~mm} / \mathrm{pixel}$ \\
\hline Pixel resolution $(\mathrm{x} / \mathrm{y})$ & $28 / 28$ & $\mu \mathrm{m} / \mu \mathrm{m}$ \\
\hline Subset resolution $(\mathrm{x} / \mathrm{y})$ & $588 / 588$ & $\mu \mathrm{m} / \mu \mathrm{m}$ \\
\hline Average speckle diameter & 100 & $\mu \mathrm{m}$ \\
\hline
\end{tabular}

Table 4. DIC image acquisition frequency for the fatigue tests.

\begin{tabular}{cc}
\hline Cycle Count & Image Taken Every (x) Cycles \\
\hline $0-500$ & 20 \\
\hline $500-10^{3}$ & 50 \\
\hline $10^{3}-10^{4}$ & 200 \\
\hline $10^{4}-\mathrm{N}$ & $10^{3}$ \\
\hline
\end{tabular}

\section{Results and Discussion}

\section{1. $S-N_{f}$ Data}

The initial information derived from any fatigue experimental campaign is the $S-\mathrm{N}_{\mathrm{f}}$ data. In Figure 4, the S- $\mathrm{N}_{\mathrm{f}}$ data for the unbalanced laminates are initially plotted for $\mathrm{R}=0.1$. On the $x$-axis, the cycles to failure $\mathrm{N}_{\mathrm{f}}$ are plotted on a logarithmic scale. On the $y$-axis, the $\sigma_{\max }$ values are plotted on a linear scale. The filled data points mean that $\mathrm{N}_{\mathrm{f}}$ was less than $10^{6}$ cycles, whereas the unfilled ones indicate run-outs, meaning that the corresponding specimen reached the run-out limit of one million cycles. The grey arrows also designate the same for clarity. Keeping in mind the generally stochastic response of composite materials under fatigue loads, the obtained results present a good repeatability, with data points corresponding to the same fatigue conditions being always in the same order of magnitude. It can be noticed from Figure 4 that the $\left[0^{\circ} / 60^{\circ}\right]_{2 s}$ laminates lead to a generally better fatigue behaviour in terms of the cycles to final failure than the $\left[0^{\circ} / 30^{\circ}\right]_{2 \mathrm{~s}}$ laminates. Run-outs are observed in both cases when the maximum fatigue stress is equal to $60 \%$ of $\sigma_{\text {ult }}$. This can be explained by the fact that carbon/epoxy laminates are quite fatigue resistant. This means that any difference in the fatigue behaviour is revealed only at high fatigue loads, explaining thus the choice of the high stress levels for the fatigue experimental campaign. It can be seen from Figure 4 that when $R=0.1$, the $\left[0^{\circ} / 60^{\circ}\right]_{2 s}$ laminates lead to run-out even for $\sigma_{\max }$ equal to $70 \%$ of $\sigma_{\text {ult }}$, whereas this is not the case for the $\left[0^{\circ} / 30^{\circ}\right]_{2 \mathrm{~s}}$ laminates which fail after $3-7 \times 10^{5}$ cycles. This difference is also obvious when the maximum fatigue stress equals $80 \%$ of $\sigma_{\text {ult }}$, with the $\left[0^{\circ} / 30^{\circ}\right]_{2 \mathrm{~s}}$ laminates failing after 3-9 $\times 10^{4}$ cycles, whereas $\mathrm{N}_{\mathrm{f}}$ is in the order of $10^{5}$ cycles for the $\left[0^{\circ} / 60^{\circ}\right]_{2 \mathrm{~s}}$ laminates. This behaviour is inversed for the very high fatigue loads with $\sigma_{\max }$ equalling $90 \%$ of $\sigma_{\text {ult }}$. In this case, both laminates lead to fatigue lives of some thousands of cycles, with the $\left[0^{\circ} / 60^{\circ}\right]_{2 \mathrm{~s}}$ laminates being characterised by relatively fewer cycles to failure. 


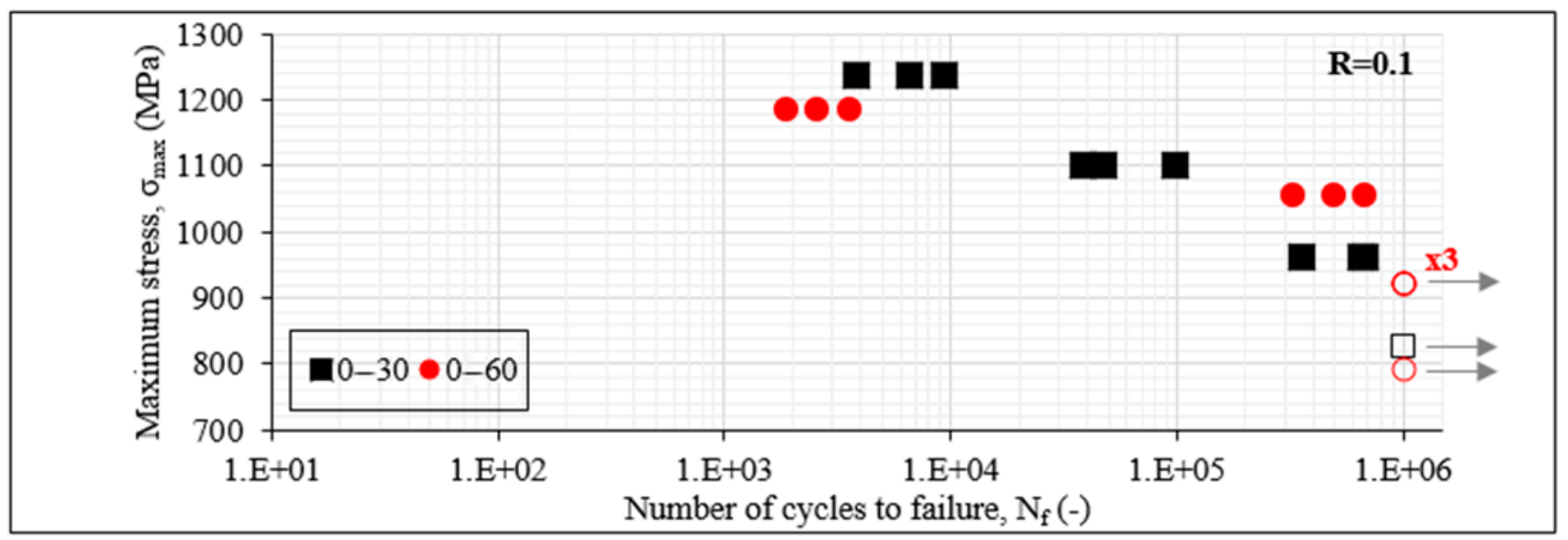

Figure 4. S-N $\mathrm{N}_{\mathrm{f}}$ data of $\left[0^{\circ} / 30^{\circ}\right]_{2 \mathrm{~s}}$ and $\left[0^{\circ} / 60^{\circ}\right]_{2 \mathrm{~s}}$ laminates for $\mathrm{R}=0.1$.

As a first conclusion, it can be assumed that the high shear stresses in the off-axis layers of the $\left[0^{\circ} / 30^{\circ}\right]_{2 s}$ laminates lead to quicker degradation of the material and consequently to lower fatigue life. This is confirmed later by the detailed damage investigations. The oppositeness for the very high fatigue loads can be attributed to the high matrix crack densities occurring in the $\left[0^{\circ} / 60^{\circ}\right]_{2 s}$ laminates, leading in this case more quickly to catastrophic failure, however without significant differences in the $\mathrm{N}_{\mathrm{f}}$ values.

To confirm the previous results, in Figure 5, the S- $\mathrm{N}_{\mathrm{f}}$ data for the $\left[0^{\circ} / \theta / 0^{\circ} /-\theta\right]_{\mathrm{s}}$ laminates for both angles and for $\mathrm{R}$ equal to 0.1 are plotted. In this case, the influence of the different multiaxial stresses is much more obvious. The balanced $\left[0^{\circ} / 60^{\circ} / 0^{\circ} /-60^{\circ}\right]_{\mathrm{s}}$ laminates lead to significantly better fatigue response than the $\left[0^{\circ} / 30^{\circ} / 0^{\circ} /-30^{\circ}\right]_{s}$ laminates. Both lead to run-out when $\sigma_{\max }$ equals $60 \%$ of $\sigma_{\text {ult }}$. The $\left[0^{\circ} / 60^{\circ} / 0^{\circ} /-60^{\circ}\right]_{s}$ laminates lead then always to higher fatigue life for all stress levels, even if $\sigma_{\max }$ is similar in both cases. This is also confirmed from Figure 6 plotting the $\mathrm{S}-\mathrm{N}_{\mathrm{f}}$ data for the $\left[0^{\circ} / \theta /-\theta\right]_{2 \mathrm{~s}}$ laminates. In addition, in this case, the shear-dominated $\left[0^{\circ} / 30^{\circ} /-30^{\circ}\right]_{2 s}$ laminates are characterised by lower fatigue lives than the $\left[0^{\circ} / 60^{\circ} /-60^{\circ}\right]_{2 \mathrm{~s}}$ laminates in which the transverse stresses dominate in the off-axis layers. Apart from the $60 \%$ maximum fatigue stress case, at which both laminates lead to run-out, for the rest of the stress levels, the $\left[0^{\circ} / 60^{\circ} /-60^{\circ}\right]_{2 \mathrm{~s}}$ laminates fail always after a higher number of cycles. A characteristic example is that for $\sigma_{\max }$ equal to $70 \%$ of $\sigma_{\text {ult }}$, the $\left[0^{\circ} / 60^{\circ} /-60^{\circ}\right]_{2 \mathrm{~s}}$ laminates fail after $6-7 \times 10^{5}$ cycles, whereas the $\left[0^{\circ} / 30^{\circ} /-30^{\circ}\right]_{2 s}$ laminates have a fatigue life in the range of only $1-3 \times 10^{5}$ cycles, which means that their fatigue life is less than half of the $\left[0^{\circ} / 60^{\circ} /-60^{\circ}\right]_{2 s}$ laminates.

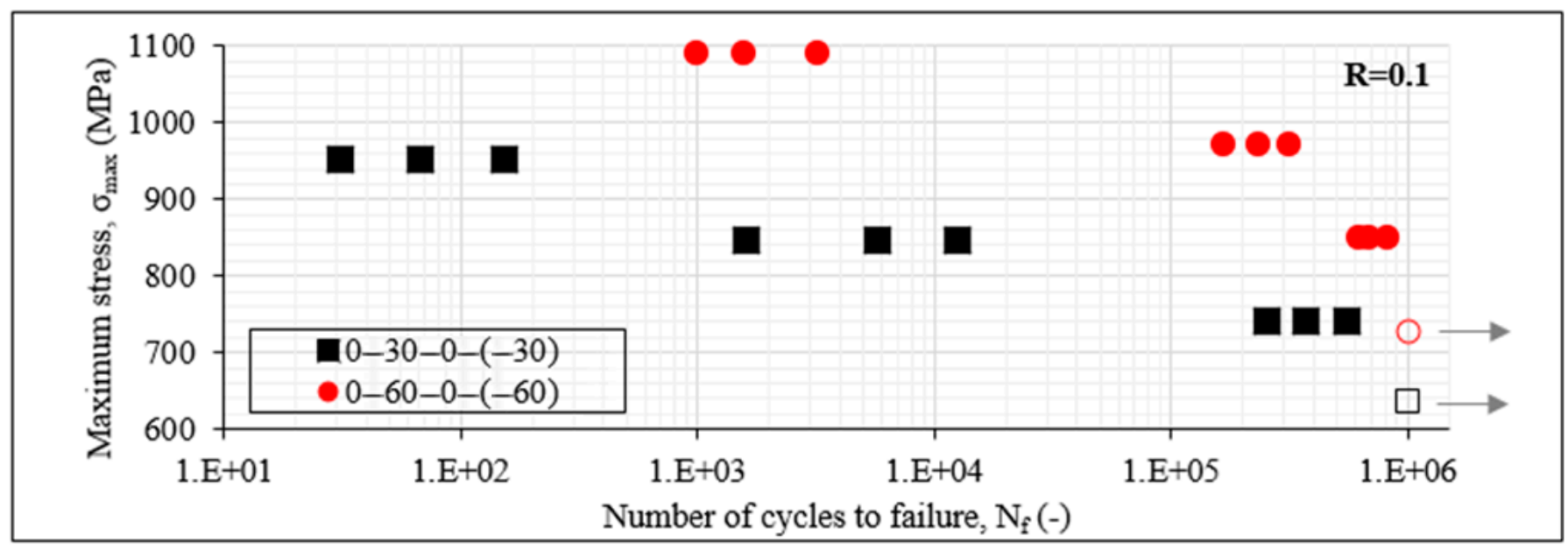

Figure 5. S- $\mathrm{N}_{\mathrm{f}}$ data of $\left[0^{\circ} / 30^{\circ} / 0^{\circ} /-30^{\circ}\right]_{\mathrm{s}}$ and $\left[0^{\circ} / 60^{\circ} / 0^{\circ} /-60^{\circ}\right]_{\mathrm{s}}$ laminates for $\mathrm{R}=0.1$. 


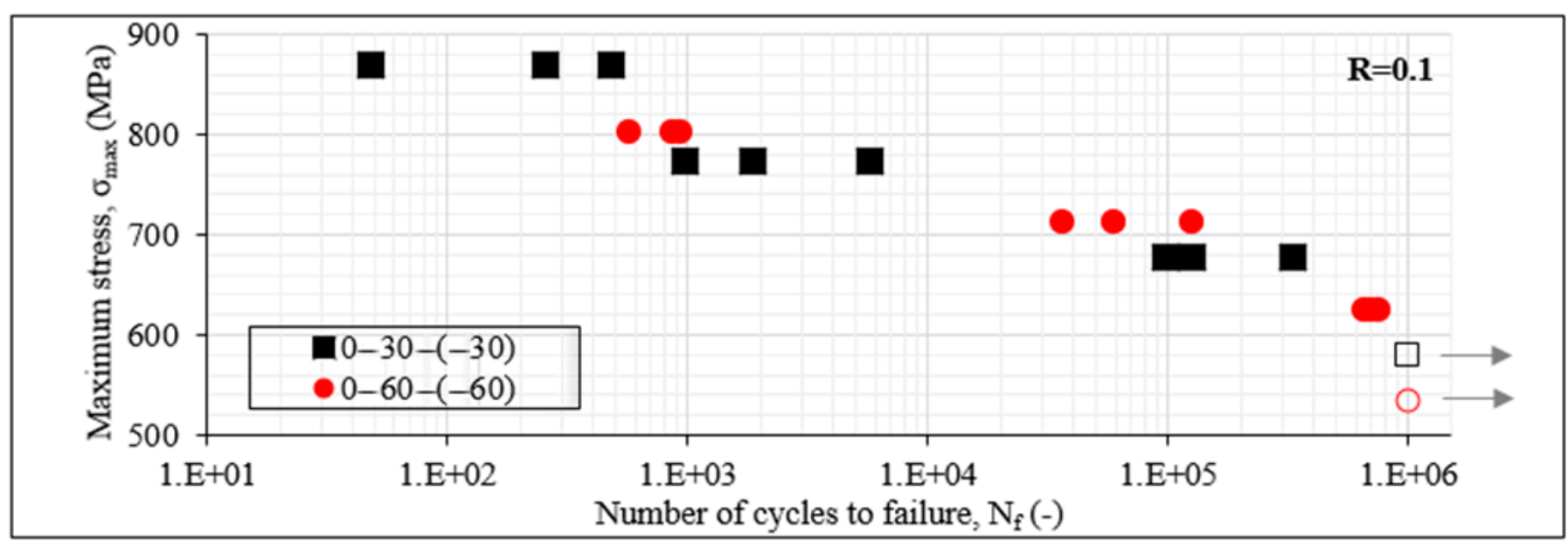

Figure 6. S- $\mathrm{N}_{\mathrm{f}}$ data of $\left[0^{\circ} / 30^{\circ} /-30^{\circ}\right]_{2 \mathrm{~s}}$ and $\left[0^{\circ} / 60^{\circ} /-60^{\circ}\right]_{2 \mathrm{~s}}$ laminates for $\mathrm{R}=0.1$.

Comparing the unbalanced with the balanced laminates in terms of their fatigue life in Figures 4 and 5, the potential of the first ones is revealed. For all stress cases, the unbalanced laminates fail after a higher number of cycles. Indicatively, for the $90 \%$ case, a big difference appears between the $\left[0^{\circ} / 30^{\circ}\right]_{2 s}$ and $\left[0^{\circ} / 30^{\circ} / 0^{\circ} /-30^{\circ}\right]_{s}$ laminates, with the first ones failing after some thousands of cycles, while the latter ones only survive for some dozens of cycles. These findings agree with the results obtained after the analysis of static tests [40], showing that unbalanced laminates can perform better than balanced ones, delaying the onset and propagation of damage.

Trying to explain the influence of the number of the off-axis layers on the fatigue response of the material by comparing Figures 5 and 6, the impact is more obvious for the $60^{\circ}$ angle case. If the 8-ply $\left[0^{\circ} / 60^{\circ} / 0^{\circ} /-60^{\circ}\right]_{s}$ laminates are compared with the 12-ply $\left[0^{\circ} / 60^{\circ} /-60^{\circ}\right]_{2 \mathrm{~s}}$ laminates, it is obvious that the last ones have a worse fatigue behaviour, leading to three times lower fatigue lives on average for the $80 \%$ and $90 \%$ stress cases. The influence is smaller for the $30^{\circ}$ off-axis angle, with the $\left[0^{\circ} / 30^{\circ} /-30^{\circ}\right]_{2 \mathrm{~s}}$ laminates leading to similar fatigue lives with the $\left[0^{\circ} / 30^{\circ} / 0^{\circ} /-30^{\circ}\right]_{\mathrm{S}}$ laminates. This could be related to the multiple interfaces in the 12-ply lay-up which accumulate the damage at independent regions without crucial propagation, as is discussed later.

The previous results related to the impact of shear, the comparison between unbalanced and balanced laminates and the influence of the number of the off-axis layers were confirmed for an R-ratio equal to 0.5 as well. In all cases, the R-ratio seemed to have a great impact on the fatigue life, with higher fatigue lives being registered for all laminates and for all considered stress cases for an R-ratio equal to 0.5 , corresponding to a lower stress amplitude during the fatigue loading. This impact is indicatively presented in Figure 7, plotting the $\mathrm{S}-\mathrm{N}_{\mathrm{f}}$ data for the $\left[0^{\circ} / \theta / 0^{\circ} /-\theta\right]_{\mathrm{s}}$ laminates for $\mathrm{R}=0.5$. Both laminates are characterised by much higher fatigue lives when the R-ratio is increased (compared to Figure 5). As an example, the fatigue life of the $\left[0^{\circ} / 30^{\circ} / 0^{\circ} /-30^{\circ}\right]_{s}$ laminates increases by 64 times when $\sigma_{\max }$ equals $80 \%$ of $\sigma_{\text {ult }}$, just by increasing the R-ratio from 0.1 to 0.5 . 


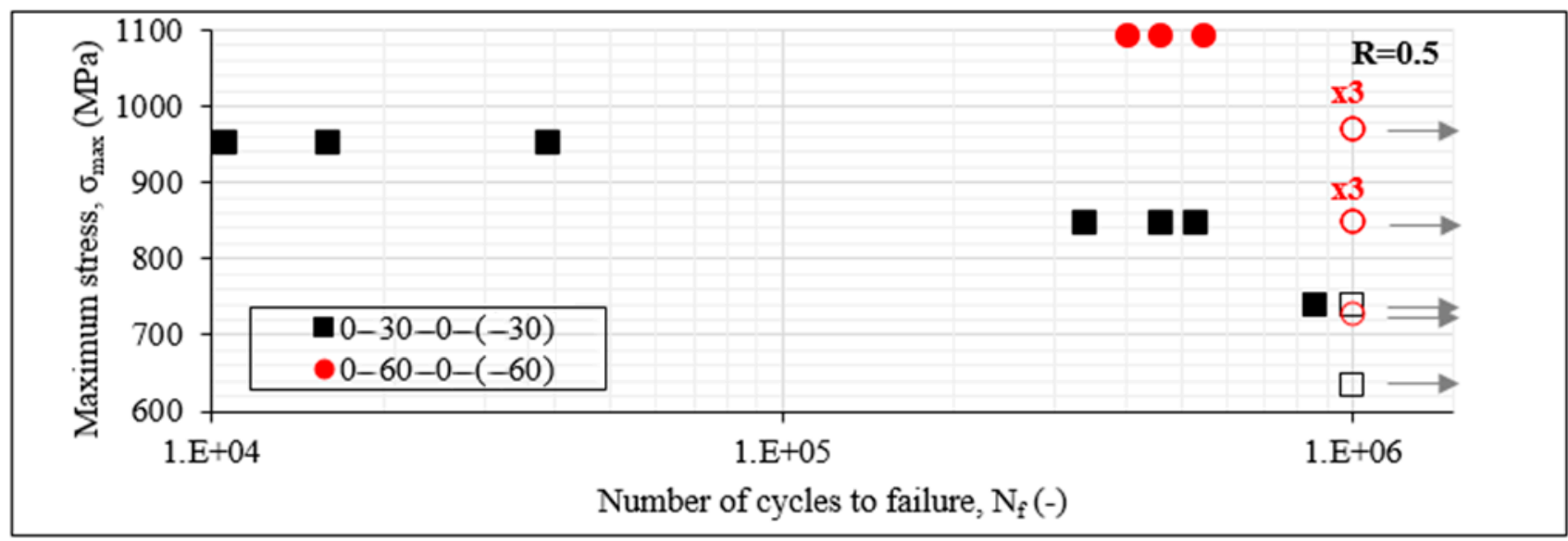

Figure 7. S- $\mathrm{N}_{\mathrm{f}}$ data of $\left[0^{\circ} / 30^{\circ} / 0^{\circ} /-30^{\circ}\right]_{\mathrm{s}}$ and $\left[0^{\circ} / 60^{\circ} / 0^{\circ} /-60^{\circ}\right]_{\mathrm{s}}$ laminates for $\mathrm{R}=0.5$.

\subsection{Residual Strength Measurements}

Specimens that survived the fatigue experiment of $10^{6}$ cycles were subjected to static tensile tests with a displacement rate of $1 \mathrm{~mm} / \mathrm{min}$ to calculate their residual strength $\sigma_{\text {res }}$. In Figure $8 \mathrm{a}-\mathrm{c}$, the average ratio $\sigma_{\text {res }} / \sigma_{\text {ult }}$ versus the maximum fatigue stress $\sigma_{\max }$ for both R-ratios, 0.1 and 0.5 , is plotted, respectively, for the unbalanced $\left[0^{\circ} / \theta\right]_{2 \mathrm{~s}}$, the 8-ply balanced $\left[0^{\circ} / \theta / 0^{\circ} /-\theta\right]_{s}$ and the 12-ply $\left[0^{\circ} / \theta /-\theta\right]_{2 s}$ specimens that reached the run-out value. By looking first at Figure $8 \mathrm{a}$, the shear influence is once more evident. The $\left[0^{\circ} / 30^{\circ}\right]_{2 \mathrm{~s}}$ laminates lead to a notably higher drop in their final strength compared to the $\left[0^{\circ} / 60^{\circ}\right]_{2 \mathrm{~s}}$ laminates after having survived one million fatigue cycles. The residual strength becomes smaller when the maximum fatigue stress increases, and a drop even higher than $10 \%$ is observed for the $\left[0^{\circ} / 30^{\circ}\right]_{2 \mathrm{~s}}$ laminates when $\sigma_{\max }$ reaches $90 \%$ of $\sigma_{\text {ult }}$ and $\mathrm{R}=0.5$. The influence of the R-ratio is also clear and quite detrimental. When $\mathrm{R}=0.1$, the drop of $10 \%$ in strength is observed when $\sigma_{\max }$ equals only $60 \%$ of $\sigma_{\text {ult }}$, i.e., during the application of quite lower fatigue loads. On the other hand, in the $\left[0^{\circ} / 60^{\circ}\right]_{2 s}$ laminates, higher $\sigma_{\text {res }} / \sigma_{\text {ult }}$ values are observed. It is remarkable that even an increase in the final strength is obtained when $\sigma_{\max }$ equals $60 \%$ of $\sigma_{\text {ult }}$ for both values of R. This can be attributed to the limited extent of damage in the unbalanced $\left[0^{\circ} / 60^{\circ}\right]_{2 s}$ laminates under such low loads together with a potential re-alignment of the $60^{\circ}$ layers, resulting in a lower inclination with respect to the loading direction. The impact of the R-ratio and the increasing $\sigma_{\max }$ values on the residual strength is nevertheless the same for both unbalanced laminates.

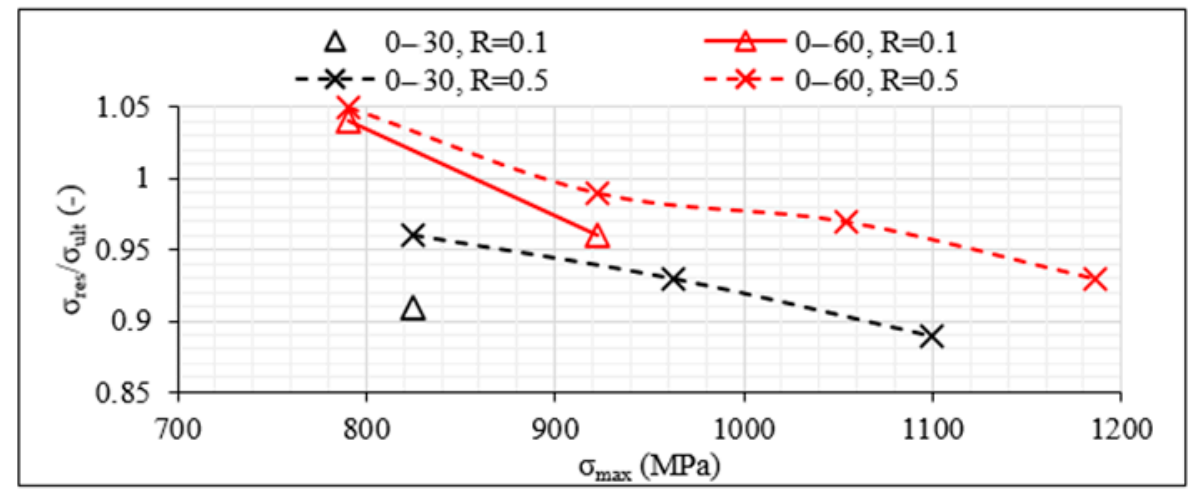

(a)

Figure 8. Cont. 


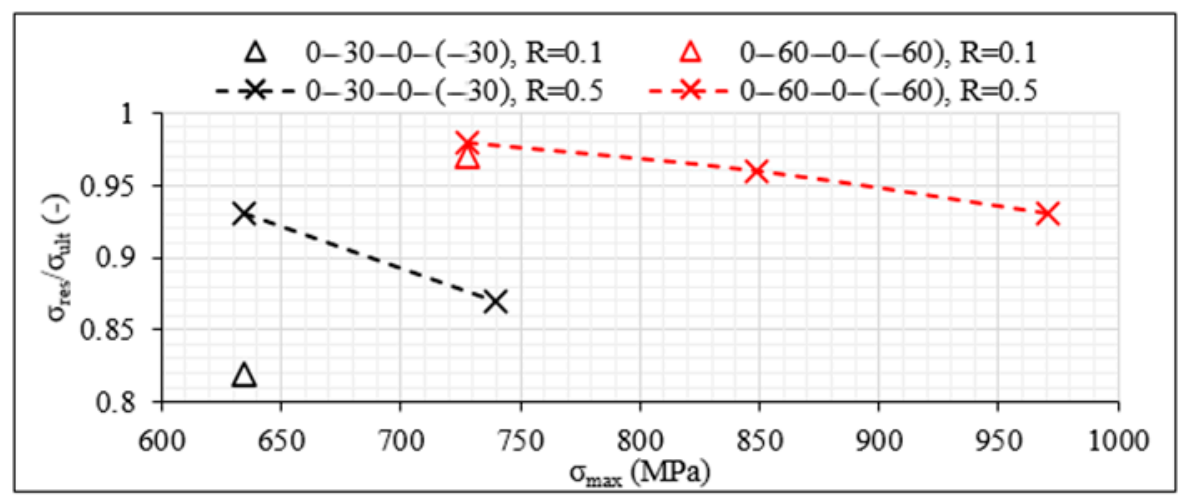

(b)

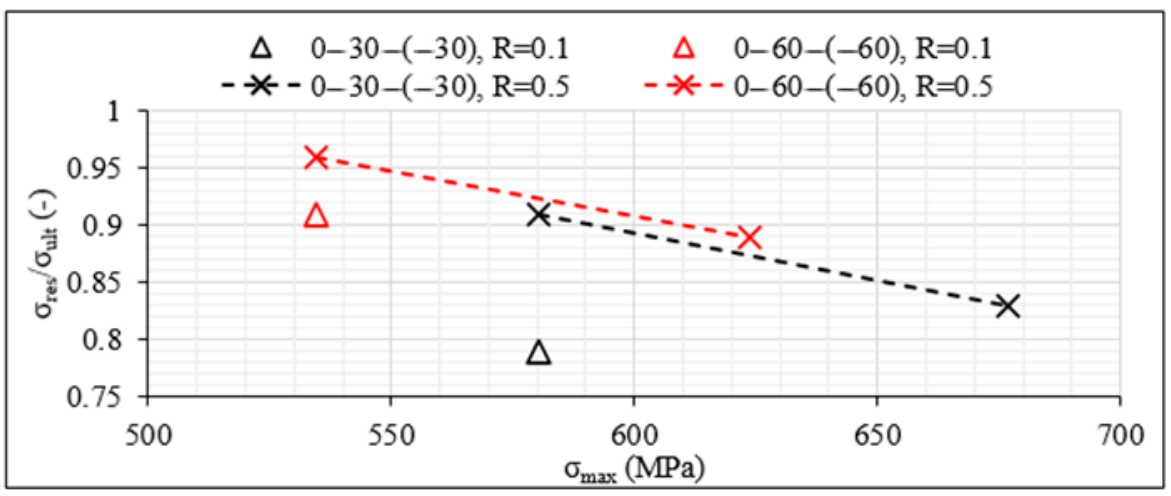

(c)

Figure 8. $\sigma_{\text {res }} / \sigma_{\text {ult }}$ values versus $\sigma_{\max }$ obtained for (a) $\left[0^{\circ} / \theta\right]_{2 s}$, (b) $\left[0^{\circ} / \theta / 0^{\circ} /-\theta\right]_{\mathrm{s}}$ and (c) $\left[0^{\circ} / \theta /-\theta\right]_{2 \mathrm{~s}}$ laminates.

By looking at Figure 8b,c, the shear influence is also confirmed for the balanced 8-ply and 12-ply laminates, with specimens including $30^{\circ}$ off-axis layers being characterised by higher drops in $\sigma_{\text {res }}$. The same applies for the impact of the R-ratio with lower values, related to higher fatigue amplitude, leading always to a higher reduction of the final strength of the laminates after one million cycles. All previously discussed observations regarding the higher fatigue resistance of the unbalanced laminates are confirmed when the residual strength is studied. In all cases and for both off-axis angles, the drop in final strength is always higher for the balanced laminates. A characteristic example can be seen for the case of $\sigma_{\max }$ equalling $60 \%$ of $\sigma_{\text {ult }}$. The $\left[0^{\circ} / 30^{\circ}\right]_{2 s}$ laminates are characterised by $9 \%$ drop in strength for $\mathrm{R}=0.1$, whereas for the same maximum fatigue stress and the same $\mathrm{R}$-ratio, the corresponding drop for the $\left[0^{\circ} / 30^{\circ} / 0^{\circ} /-30^{\circ}\right]_{\mathrm{s}}$ laminates is double, namely $18 \%$. Similar conclusions are drawn when examining the impact of the number of off-axis layers. Indicatively, for $\sigma_{\max }$ equalling $60 \%$ of $\sigma_{\text {ult }}$ and $R=0.1$, the $\sigma_{\text {res }} / \sigma_{\text {ult }}$ value equals 0.91 for the 12-ply $\left[0^{\circ} / 60^{\circ} /-60^{\circ}\right]_{2 s}$ laminates, whereas it is equal to 0.97 for the 8-ply $\left[0^{\circ} / 60^{\circ} / 0^{\circ} /-60^{\circ}\right]_{\mathrm{S}}$ laminates. It should be highlighted that for the same stress conditions, this ratio equals 1.04 for the unbalanced $\left[0^{\circ} / 60^{\circ}\right]_{2 s}$ lay-up.

\subsection{Investigation of Damage Accumulation}

After a thorough experimental campaign of the considered laminates under quasistatic loading [40], it was revealed that matrix cracking is not necessarily the primary damage mode occurring in CFRPs when dominant shear stresses are developed. However, it is well known that matrix cracking is the initial damage mode occurring in composite materials during fatigue. Nevertheless, the onset of matrix cracking and the initiation of consequent interlaminar delaminations depend on many parameters, including the ones examined in this study. 


\subsubsection{Damage Accumulation in Laminates with $60^{\circ}$ Layers}

The analysis starts with the laminates with $60^{\circ}$ layers, in which the domination of the transverse stresses triggers more directly the initiation of matrix cracks. In these laminates, matrix cracking of all off-axis layers along the total gauge length was always the primary damage mode occurring during fatigue loading. In Figure $9 a$, the average evolution of the measured matrix crack density versus the number of cycles $\mathrm{N}$ (on a logarithmic scale) is plotted for the unbalanced $\left[0^{\circ} / 60^{\circ}\right]_{2 \mathrm{~s}}$ laminates for $\mathrm{R}=0.1$ and for the three maximum fatigue stress levels (i.e., $70 \%, 80 \%$ and $90 \%$ of $\sigma_{\text {ult }}$ ). A distinction between the cracks in the thick layer (middle pair of $60^{\circ}$ layers), represented by the blue curves, and the thin single $60^{\circ}$ layers, corresponding to the orange lines, is made. It is obvious that matrix cracks initiate with a high rate from the first cycles saturating as the test continues. Increasing the fatigue stress level leads to higher matrix crack density, and greater densities are observed in the thin off-axis plies. It is also notable that the higher the $\sigma_{\max }$, the quicker the crack saturation occurs, whereas the rate is smaller for lower stress levels. In order to reveal the impact of the R-ratio, in Figure 9b, the corresponding results for $R=0.5$ are shown. It is obvious that significantly lower crack density values are observed due to the lower stress amplitude related to the higher R-ratio. Despite the fact that in this case as well the crack density shows an increasing trend when $\sigma_{\max }$ increases, the densities measured in the thick and thin plies are much closer at the same stress level. Moreover, it should be mentioned that the cracking rate is lower when $\mathrm{R}=0.5$ and that saturation does not even occur in some cases, especially for the lower stress levels.

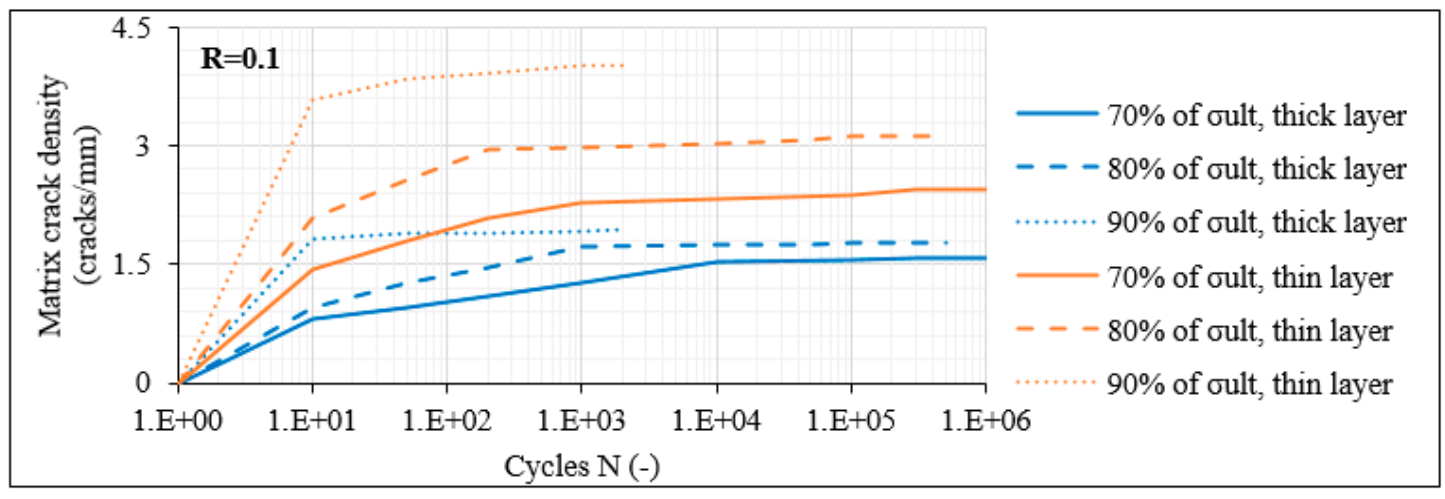

(a)

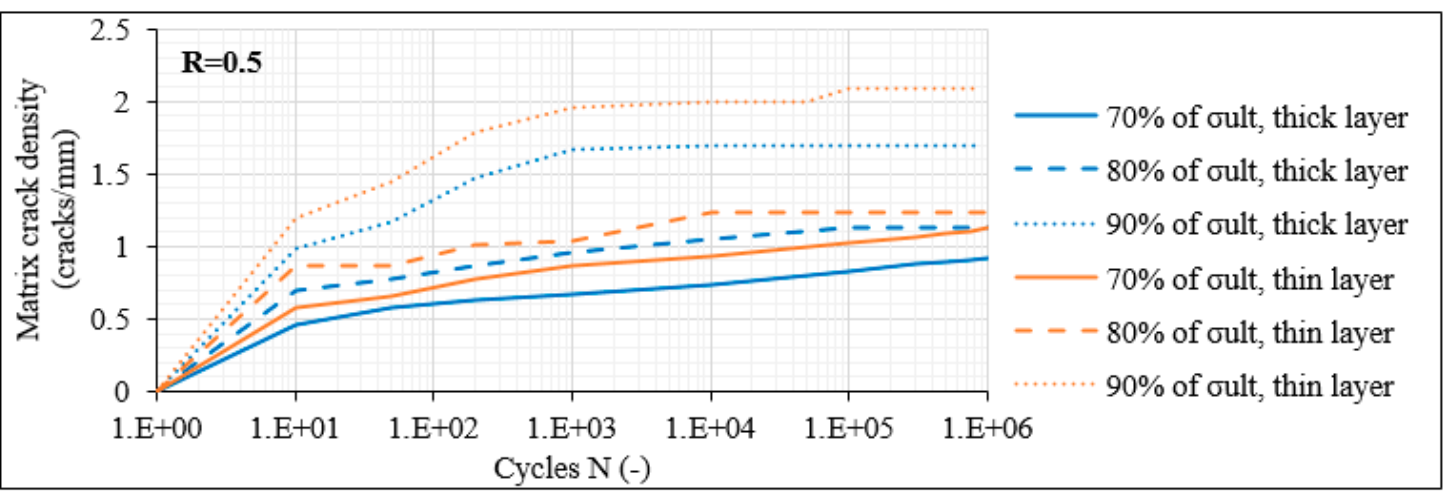

(b)

Figure 9. Matrix crack density versus $\mathrm{N}$ in $\left[0^{\circ} / 60^{\circ}\right]_{2 \mathrm{~s}}$ laminates for $(\mathbf{a}) \mathrm{R}=0.1$ and $(\mathbf{b}) \mathrm{R}=0.5$.

To demonstrate the delamination behaviour in the $\left[0^{\circ} / 60^{\circ}\right]_{2 \mathrm{~s}}$ laminates, in Figure 10a the average delamination crack growth versus $\mathrm{N}$ is plotted for $\mathrm{R}=0.1$. A differentiation between the delaminations along the interfaces of the outer $0^{\circ}$ layers and the adjacent $60^{\circ}$ layers at both sides of the laminate is performed (blue and orange curves). It is apparent 
that the initiation of delaminations is delayed and the crack growth rate is decreased when the stress level drops. As an example, when $\sigma_{\max }$ equals $80 \%$ of $\sigma_{\text {ult }}$, the first delamination appears after $200-10^{3}$ fatigue cycles on average, whereas this occurs only after $10^{3}-10^{4}$ cycles for $\sigma_{\max }$ equalling $70 \%$ of $\sigma_{\text {ult }}$. Moreover, while delaminations do appear at all examined stress levels, only in the case of $\sigma_{\max }$ equalling $90 \%$ of $\sigma_{\text {ult }}$ is a second delamination on the opposite side of the laminate also evident. In Figure 10b, the corresponding results for $\mathrm{R}=0.5$ are shown. The influence of the R-ratio is evident. For the same stress level, delaminations appear much later in the fatigue life of the laminate when $\mathrm{R}=0.5$. A characteristic example is that for $\sigma_{\max }$ equal to $80 \%$ of $\sigma_{\text {ult }}$, the first delamination appears after $200-10^{3}$ cycles for $\mathrm{R}=0.1$ and only after $10^{5}$ cycles when $\mathrm{R}=0.5$. For the $70 \%$ stress level case, no delamination appeared during the whole duration of the fatigue test with $\mathrm{R}=0.5$. Moreover, no delamination at the other laminate side was monitored for all stress levels. These trends related to the influence of the R-ratio were confirmed for all laminates under consideration.

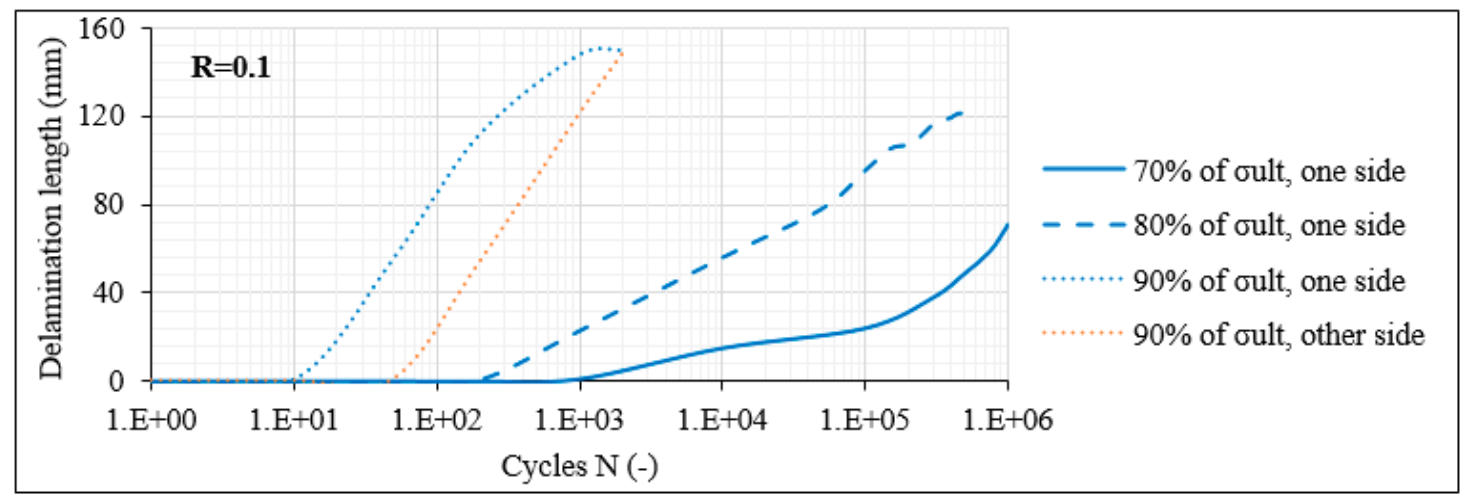

(a)

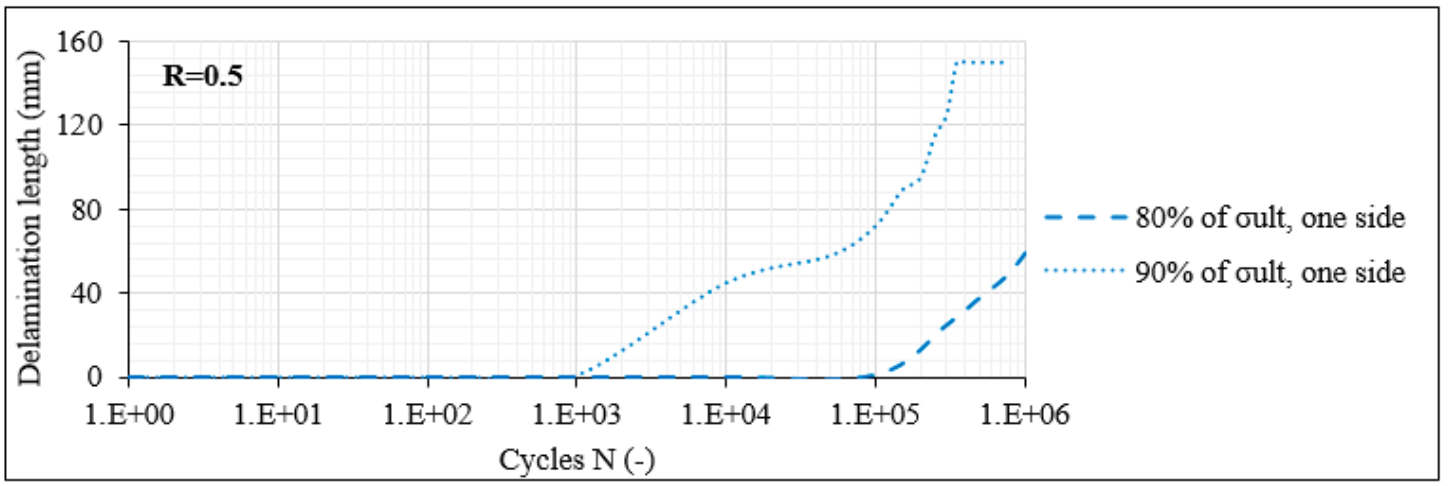

(b)

Figure 10. Delamination crack growth versus $\mathrm{N}$ in $\left[0^{\circ} / 60^{\circ}\right]_{2 \mathrm{~s}}$ laminates for $(\mathbf{a}) \mathrm{R}=0.1$ and $(\mathbf{b}) \mathrm{R}=0.5$.

Based on the damage observations on the $\left[0^{\circ} / 60^{\circ}\right]_{2 s}$ laminates, it can be concluded that predictions for the initiation of interlaminar delaminations can be accomplished, based on measurements of the matrix crack density in the off-axis layers. Stemming from empirical observations, it was noticed that for all fatigue testing conditions, delaminations appeared when the matrix crack density in the off-axis layers reached a saturation level or else when the Critical Damage State (CDS) was exceeded. This observation is further confirmed by looking at the damage state of the $\left[0^{\circ} / 60^{\circ}\right]_{2 \mathrm{~s}}$ laminates for $\sigma_{\max }=0.7 \times \sigma_{\text {ult }}$ and $\mathrm{R}=0.5$. It is obvious from Figure 10b that no delamination appeared during these testing conditions. Furthermore, it is evident from Figure $9 b$ that the matrix cracks in the off-axis layers did not saturate until the end of the test, justifying the absence of delaminations until the run-out limit. 
In order to compare the fatigue damage response of the unbalanced with the balanced laminates with $60^{\circ}$ layers, the average matrix crack density measured for the $\left[0^{\circ} / 60^{\circ} / 0^{\circ} /-60^{\circ}\right]_{\mathrm{s}}$ laminates for $\mathrm{R}=0.1$ is plotted in Figure 11. It is clear that both the unbalanced and the balanced laminates result in a very similar fracture process with the initiation of matrix cracks at the very early fatigue cycles and the subsequent initiation and propagation of delaminations. As a first remark, it can be seen that the crack density in the $\left[0^{\circ} / 60^{\circ} / 0^{\circ} /-60^{\circ}\right]_{\mathrm{s}}$ laminates reaches very similar values as in the $\left[0^{\circ} / 60^{\circ}\right]_{2 \mathrm{~s}}$ laminates for the same stress level, with slightly higher values recorded in the balanced laminates, which always increase when the maximum fatigue stress elevates. Moreover, constantly higher values are reported also in this case for the thin layers, compared to the thick ones. Nevertheless, one important difference is observed when comparing the crack densities between the balanced and the unbalanced laminates. It is clear from Figures $9 \mathrm{a}$ and 11 that for the same $\sigma_{\max }$ level, the saturation of the matrix cracks occurs earlier in the balanced laminates, meaning that the crack rate is significantly higher in this case. As an example, for the $70 \%$ $\sigma_{\max }$ case, the saturation of the cracks occurs after $10^{4}$ and $10^{3}$ cycles for the thick and thin layers of the $\left[0^{\circ} / 60^{\circ}\right]_{2 \mathrm{~s}}$ laminates, respectively, whereas the same phenomenon takes place already after $10^{3}$ and 200 cycles on average in the $\left[0^{\circ} / 60^{\circ} / 0^{\circ} /-60^{\circ}\right]_{\mathrm{s}}$ laminates. This is quite significant since, as discussed previously, the saturation of the cracks is directly linked to the initiation and propagation of interlaminar delaminations. Indeed, also in the case of the balanced laminates, the saturation criterion applies. In all cases, after the matrix cracks in the off-axis layers reached a plateau, interlaminar delaminations between the outer $0^{\circ}$ layer and the adjacent $60^{\circ}$ layer were nucleated shortly after. Specifically, in Figure 12, the delamination crack growth versus $\mathrm{N}$ curves for $\mathrm{R}=0.1$ are plotted. Delaminations initiate earlier than in the unbalanced lay-up for the same stress level. Moreover, the extent of damage is more detrimental in the $\left[0^{\circ} / 60^{\circ} / 0^{\circ} /-60^{\circ}\right]_{s}$ laminates. Higher delaminated lengths are measured with two outer-ply delaminations in most of the cases, even in test conditions at which no delamination appeared in the $\left[0^{\circ} / 60^{\circ}\right]_{2 s}$ laminates.

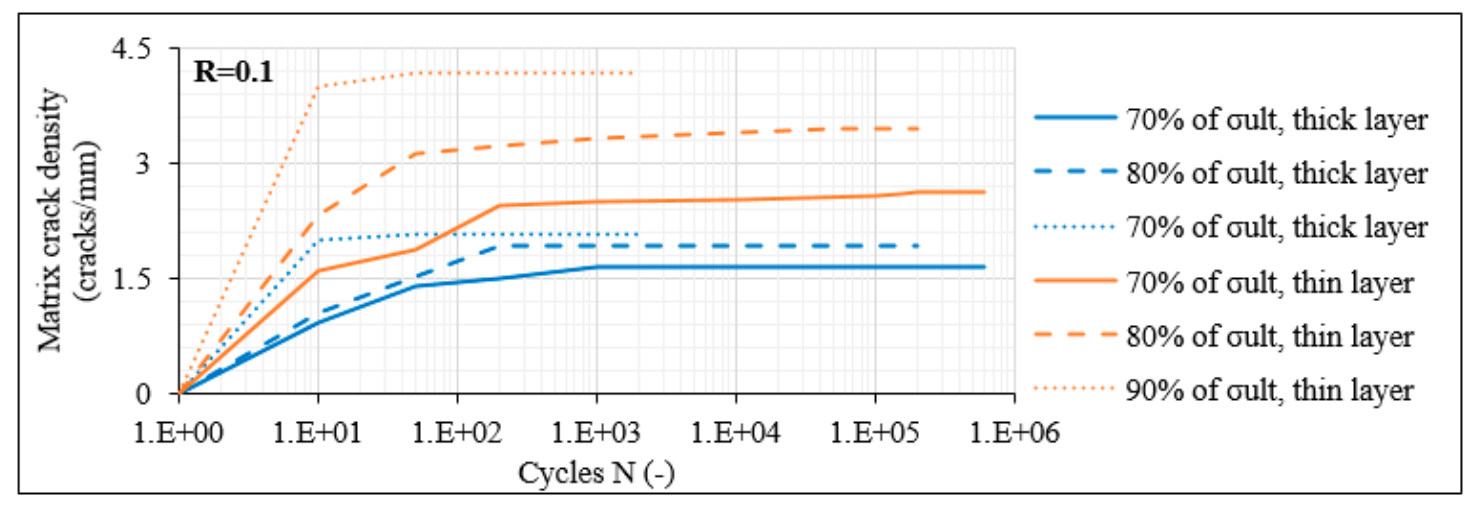

Figure 11. Matrix crack density versus $\mathrm{N}$ in $\left[0^{\circ} / 60^{\circ} / 0^{\circ} /-60^{\circ}\right]_{\mathrm{s}}$ laminates for $\mathrm{R}=0.1$.

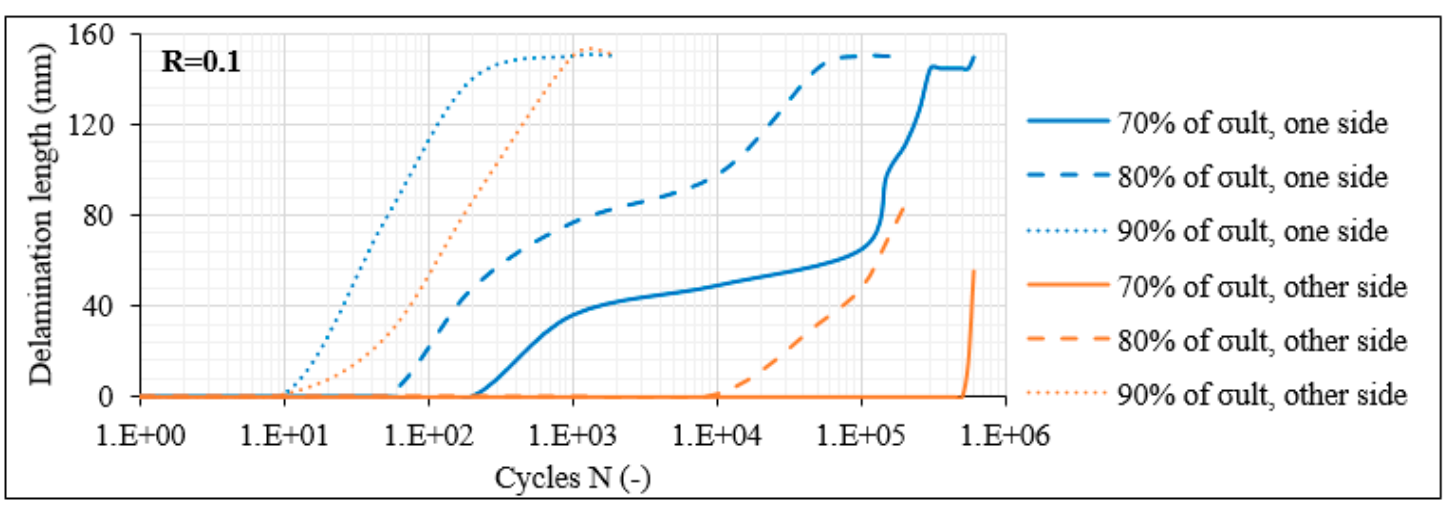

Figure 12. Delamination crack growth versus $\mathrm{N}$ in $\left[0^{\circ} / 60^{\circ} / 0^{\circ} /-60^{\circ}\right]_{\mathrm{s}}$ laminates for $\mathrm{R}=0.1$. 
In order to demonstrate the influence of the number of the off-axis plies, Figures 13 and 14 plot the matrix crack density and the delamination crack growth as measured for the $\left[0^{\circ} / 60^{\circ} /-60^{\circ}\right]_{2 \mathrm{~s}}$ laminates for $\mathrm{R}=0.1$. It should be stated here that in the case of the 12 -ply laminates, the term "thick" corresponds to the middle double $(-\theta) /(-\theta)$ layer whereas the term "thin" corresponds to the rest of the layers having no identical lamina next to them. Before describing the influence of the number of the off-axis layers on the fatigue response for $\theta=60^{\circ}$, it should be mentioned that certain similarities with the previously studied laminates also having an angle of $60^{\circ}$ are obtained. These similarities concern mainly the influence of $\sigma_{\max }$ and R-ratio. Despite these similarities, increasing the number of the off-axis layers in the laminate results in notably higher matrix crack densities in all off-axis layers.

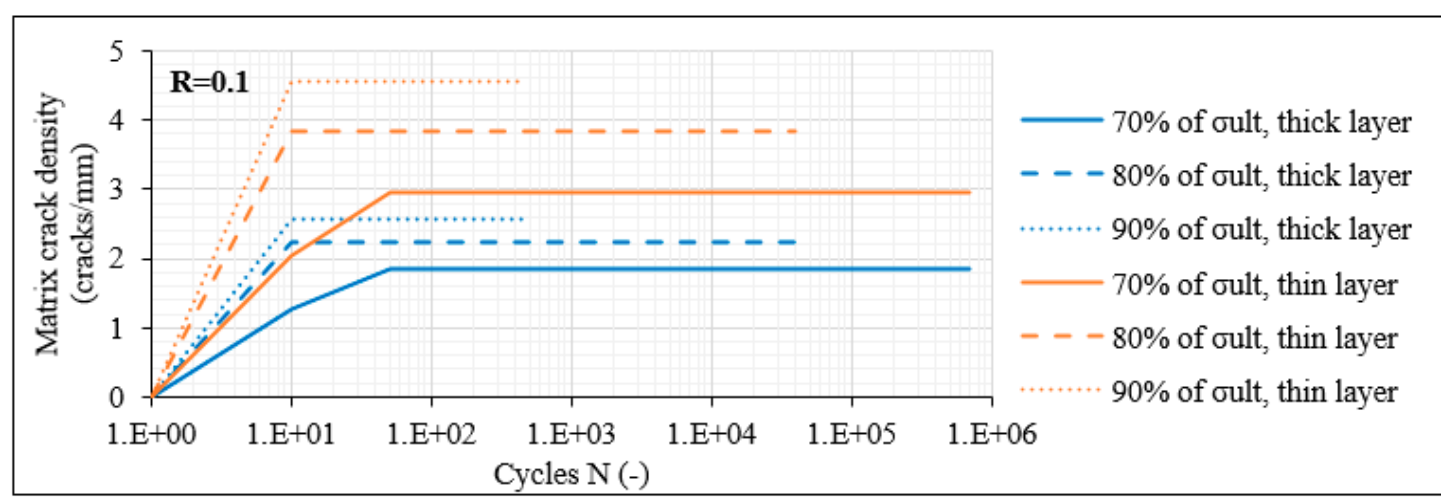

Figure 13. Matrix crack density versus $\mathrm{N}$ in $\left[0^{\circ} / 60^{\circ} /-60^{\circ}\right]_{2 \mathrm{~s}}$ laminates for $\mathrm{R}=0.1$.

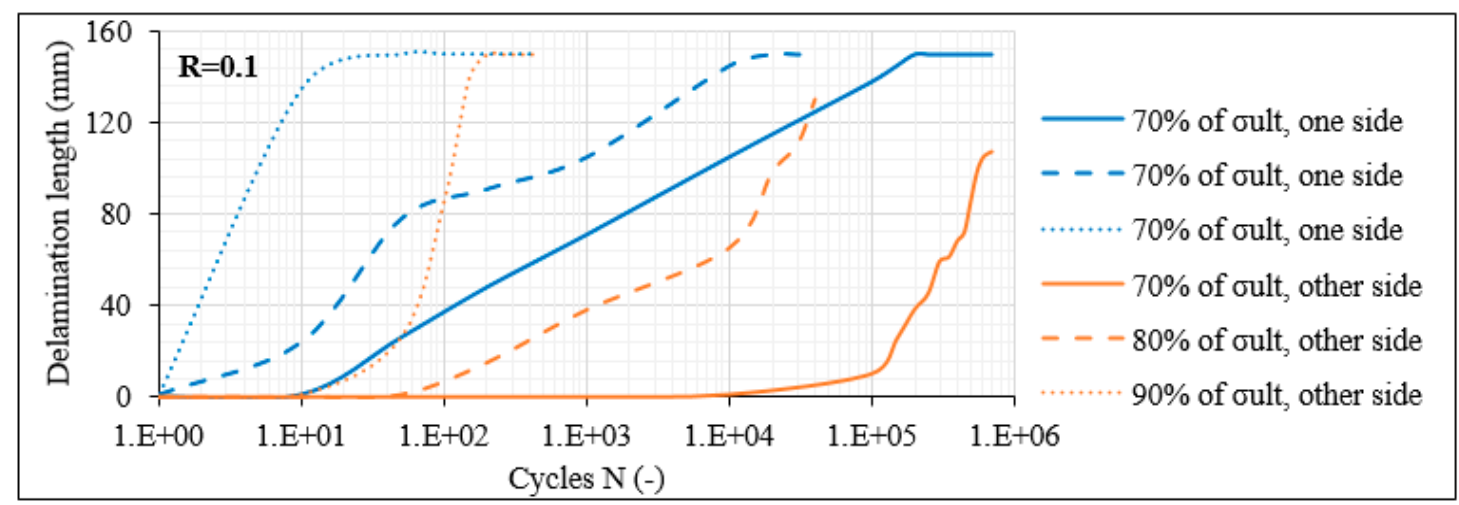

Figure 14. Delamination crack growth versus $\mathrm{N}$ in $\left[0^{\circ} / 60^{\circ} /-60^{\circ}\right]_{2 \mathrm{~s}}$ laminates for $\mathrm{R}=0.1$.

This can be related to a significantly lower fracture toughness of the 12-ply lay-up when off-axis layers with dominant $\sigma_{22}$ stresses are added. This is also evident by the fact that in this case a quite unstable fracture process was observed. While the aforementioned crack densities correspond to average values along the total gauge length, it was noticed that some laminate areas were much more deteriorated than others, with higher matrix crack densities, and that in some cases, cracks that had not propagated along the total layer thickness appeared. This was not the case in the 8-ply laminates, in which quite stable density distributions were observed with cracks covering the total lamina thickness. Moreover, it is remarkable that the crack density saturates rapidly in the 12-ply laminates, corresponding to a very high cracking rate. Indicatively for $\mathrm{R}=0.1$ and for all stress levels, the matrix crack density in all off-axis layers saturates after 50 fatigue cycles at the latest. Once again, this is really detrimental since also in this case the saturation of matrix cracks leads quickly to delaminations between the outer plies of the laminate. Regarding the delaminations in the $\left[0^{\circ} / 60^{\circ} /-60^{\circ}\right]_{2 s}$ laminates, apart from their initiation period which appears significantly earlier, the extent of damage is also more detrimental compared to the 
8-ply laminates. The delamination growth rate is significantly high, especially for rising stress levels, leading to fully delaminated interfaces quickly during the fatigue test.

\subsubsection{Damage Accumulation in Laminates with $30^{\circ}$ Layers}

To examine the shear influence on the fatigue damage of the composite material, the damage investigation in the $\left[0^{\circ} / 30^{\circ}\right]_{2 \mathrm{~s}}$ laminates is initially reported in the following. It was observed that the high shear stresses $\tau_{12}$ in the off-axis layers of the laminates had a detrimental influence especially regarding the initiation and propagation of interlaminar delaminations. Matrix cracking was also in this case the primary damage mode that occurred during the fatigue loading. Nevertheless, both the initiation period and the fracture process were different compared to the case of the $\left[0^{\circ} / 60^{\circ}\right]_{2 s}$ laminates. Specifically, matrix cracks were initially observed along the total length of the middle thick layer of the laminate, consisting of the off-axis $30^{\circ}$ layers pair. After a certain increase in the matrix crack density, interlaminar delaminations were observed between the outer $0^{\circ}$ layer and the adjacent $30^{\circ}$ layer, prior to the initiation of matrix cracks in the thin $30^{\circ}$ layers. This is apparently contradictory to the results obtained for the $\left[0^{\circ} / 60^{\circ}\right]_{2 s}$ laminates. The propagation of delaminations along the $0^{\circ} / 30^{\circ}$ interface resulted in the occurrence of cracks in the thin off-axis layers.

In Figure 15, the average matrix crack density evolution versus $\mathrm{N}$ both for the thick and the thin off-axis layers is displayed for $\mathrm{R}=0.1$. It is obvious that for every stress level, matrix cracks initiate first in the middle thick layer, and the thin layers follow. Moreover, matrix cracks in the $\left[0^{\circ} / 30^{\circ}\right]_{2 s}$ laminates do not necessarily initiate during the application of the very first fatigue cycles. As an example, while matrix cracks are monitored after 10 fatigue cycles at the $90 \%$ stress level case, they are evident after 50 cycles when $\sigma_{\max }$ equals $70 \%$ of $\sigma_{\text {ult }}$. The higher the maximum fatigue stress applied, the sooner the occurrence of multiple cracks in the thick layer is observed. The same applies for the matrix cracks nucleating in the thin layers. In all cases, a higher matrix crack density is observed in the thin layers in comparison to the thick layer as the test proceeds. Moreover, the crack rate is significantly higher in the thin $30^{\circ}$ layers. It should be also mentioned that when comparing the $\left[0^{\circ} / 30^{\circ}\right]_{2 s}$ laminates with the $\left[0^{\circ} / 60^{\circ}\right]_{2 s}$ ones, noticeably lower densities are observed in the first case. The impact of the R-ratio was also in this case confirmed, with an R-ratio of 0.5 delaying the onset and propagation of damage.

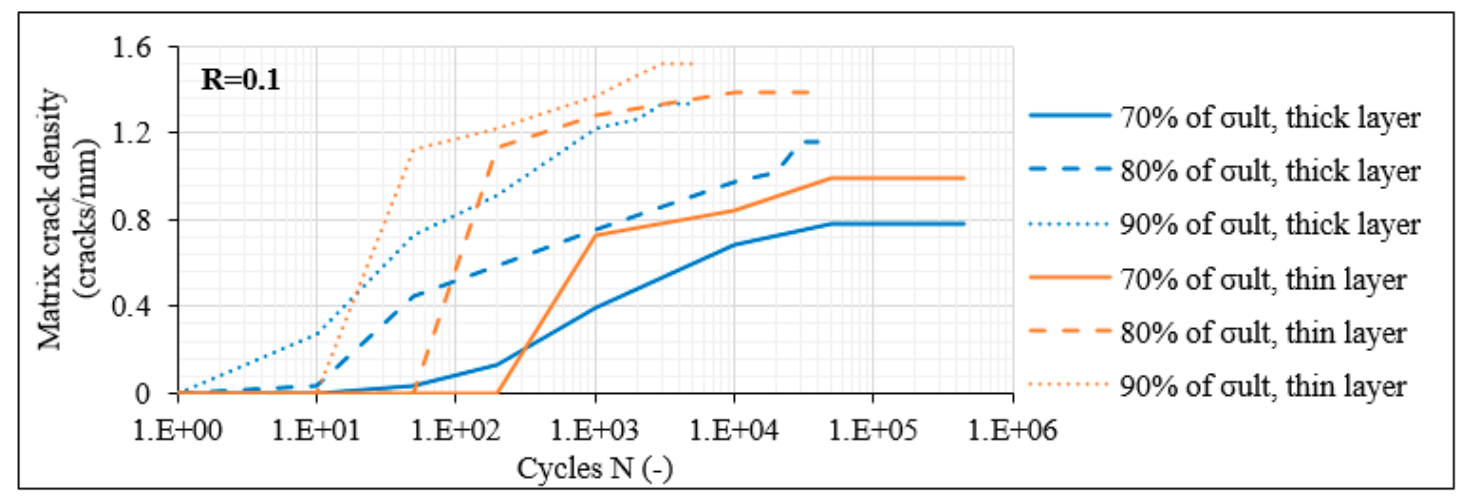

Figure 15. Matrix crack density versus $\mathrm{N}$ in $\left[0^{\circ} / 30^{\circ}\right]_{2 \mathrm{~s}}$ laminates for $\mathrm{R}=0.1$.

In Figure 16, the average delamination crack growth observed on both opposite external sides of the $\left[0^{\circ} / 30^{\circ}\right]_{2 \mathrm{~s}}$ laminates for $\mathrm{R}=0.1$ is plotted. As a first remark, in the $\left[0^{\circ} / 30^{\circ}\right]_{2 \mathrm{~s}}$ laminates, delaminations on both sides of the laminate were nucleated for all stress levels when $R$ equalled 0.1 , contrary to the $\left[0^{\circ} / 60^{\circ}\right]_{2 s}$ laminates. This provides evidence for the detrimental influence of shear when fatigue loads are applied. This destructive behaviour is also confirmed when looking at the initiation period of delaminations. As an example, initial delaminations appeared in the $\left[0^{\circ} / 30^{\circ}\right]_{2 \mathrm{~s}}$ laminates in the period $50-200$ fatigue cycles for the $70 \%$ stress level for $R=0.1$, whereas this occurred only in the period $10^{3}-10^{4}$ cycles 
in the $\left[0^{\circ} / 60^{\circ}\right]_{2 \mathrm{~s}}$ laminates for the same stress level. Similar behaviour was observed for $\mathrm{R}=0.5$. It should be mentioned that also the extent of damage was not the same in the two laminates. While in the $\left[0^{\circ} / 30^{\circ}\right]_{2 \mathrm{~s}}$ specimens, delaminations propagated along the total gauge length in most cases, this did not always happen in the $\left[0^{\circ} / 60^{\circ}\right]_{2 \mathrm{~s}}$ laminates.

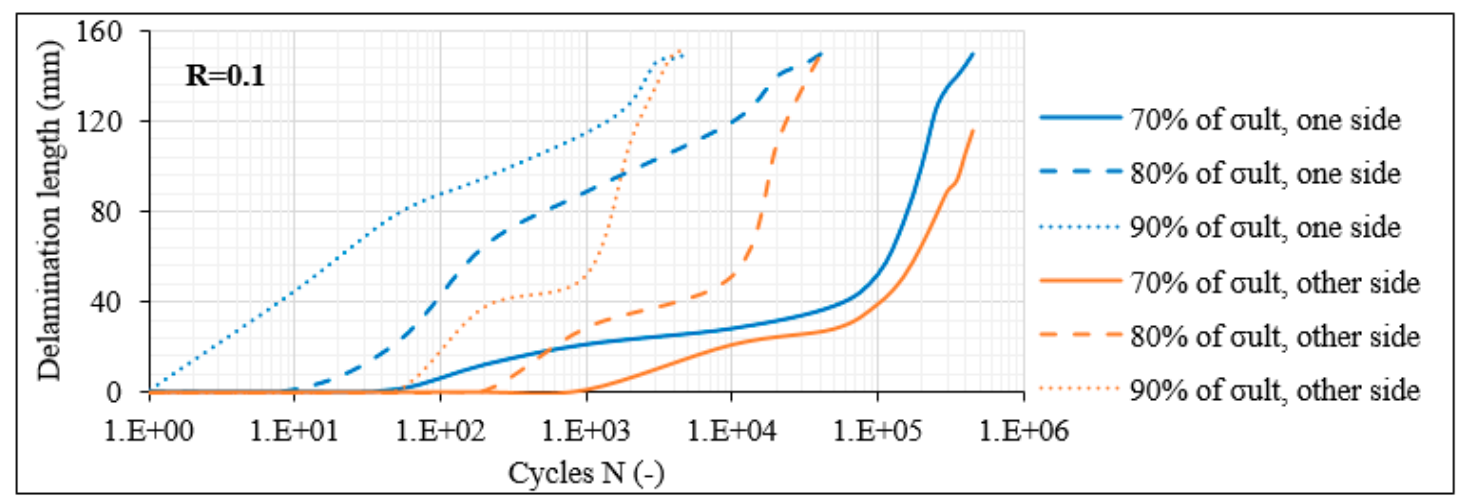

Figure 16. Delamination crack growth versus $\mathrm{N}$ in $\left[0^{\circ} / 30^{\circ}\right]_{2 \mathrm{~s}}$ laminates for $\mathrm{R}=0.1$.

Based on the damage observations discussed before, an empirical conclusion can be drawn regarding the $\left[0^{\circ} / 30^{\circ}\right]_{2 s}$ laminates. Specifically, it was observed that in all test cases interlaminar delaminations were developed at the edge of the laminate when a certain matrix crack density in the middle thick layer was reached. This CDS was different for the two R-ratios under consideration. Specifically, it was noticed that for $\mathrm{R}=0.1$, interlaminar delaminations were detected at the laminate edge when the crack density reached a value in the range $0.1-0.2 \mathrm{cracks} / \mathrm{mm}$ in the middle thick layer. For the case of $\mathrm{R}=0.5$, delaminations were observed along the $0^{\circ} / 30^{\circ}$ interface when the matrix crack density exceeded the value of 0.5 cracks $/ \mathrm{mm}$. In all cases, soon after the nucleation of delaminations, matrix cracks in both thin $30^{\circ}$ layers were observed. However, it should be highlighted that the thin off-axis layers were not immediately cracked along the total gauge length. Initial matrix cracks appeared always close to the tip of the formed delamination in both off-axis layers and new ones kept on nucleating afterward along the layer length. Nevertheless, the total length was always cracked before delamination at the opposite laminate side was evident. Furthermore, it is notable that contrary to the $\left[0^{\circ} / 60^{\circ}\right]_{2 s}$ laminates, the matrix crack density kept increasing after the nucleation and propagation of delaminations in the $\left[0^{\circ} / 30^{\circ}\right]_{2 s}$ laminates. Therefore, the matrix cracking saturation criterion for the nucleation of delaminations does not apply for the last case. The above observations show that the matrix crack density and the damage conditions that suffice for leading to the initiation of delaminations in the $\left[0^{\circ} / 30^{\circ}\right]_{2 s}$ laminates are much more limited compared to the $\left[0^{\circ} / 60^{\circ}\right]_{2 \mathrm{~s}}$ laminates. A significantly lower CDS and therefore a considerably limited generated energy are enough for delaminations to appear due to the high shear stresses in the laminas. On the other hand, despite the fact that high matrix crack densities appear in the $\left[0^{\circ} / 60^{\circ}\right]_{2 \mathrm{~s}}$ laminates, interlaminar delaminations are delayed, indicating a certain sensitivity of the composite material for the appearance of delaminations when shear is dominant.

The beneficial response of the unbalanced laminates was also revealed for the specimens with $30^{\circ}$ plies. In Figure 17, the measurements regarding the delamination lengths monitored in the $\left[0^{\circ} / 30^{\circ} / 0^{\circ} /-30^{\circ}\right]_{\mathrm{s}}$ specimens for $\mathrm{R}=0.1$ are reported. In this case, apart from the external (outer-ply) delaminations on both sides of the laminate (blue and orange curves), the length corresponding to internal (inner-ply) delaminations (green lines) is also reported. It is obvious that the balanced laminates are significantly more deteriorated in comparison to the unbalanced laminates for the same number of fatigue cycles and the same stress level. As an example, for the $80 \% \sigma_{\max }$ and $\mathrm{R}=0.1$ test case, after $10^{3}$ fatigue cycles, three delaminations already appeared and propagated along almost the total gauge length in the $\left[0^{\circ} / 30^{\circ} / 0^{\circ} /-30^{\circ}\right]_{s}$ laminates, whereas only two shorter delaminations developed 
in the unbalanced $\left[0^{\circ} / 30^{\circ}\right]_{2 \mathrm{~s}}$ laminates. At the same time, it should be highlighted that fibre fracture always accompanied the inner-ply delaminations in the balanced laminates, leading to a further deterioration of the material. It should be noticed that in the balanced laminates, the CDS for the nucleation of delaminations corresponded to 0.05 cracks $/ \mathrm{mm}$ for $R=0.1$, revealing a lower fracture toughness than the unbalanced ones.

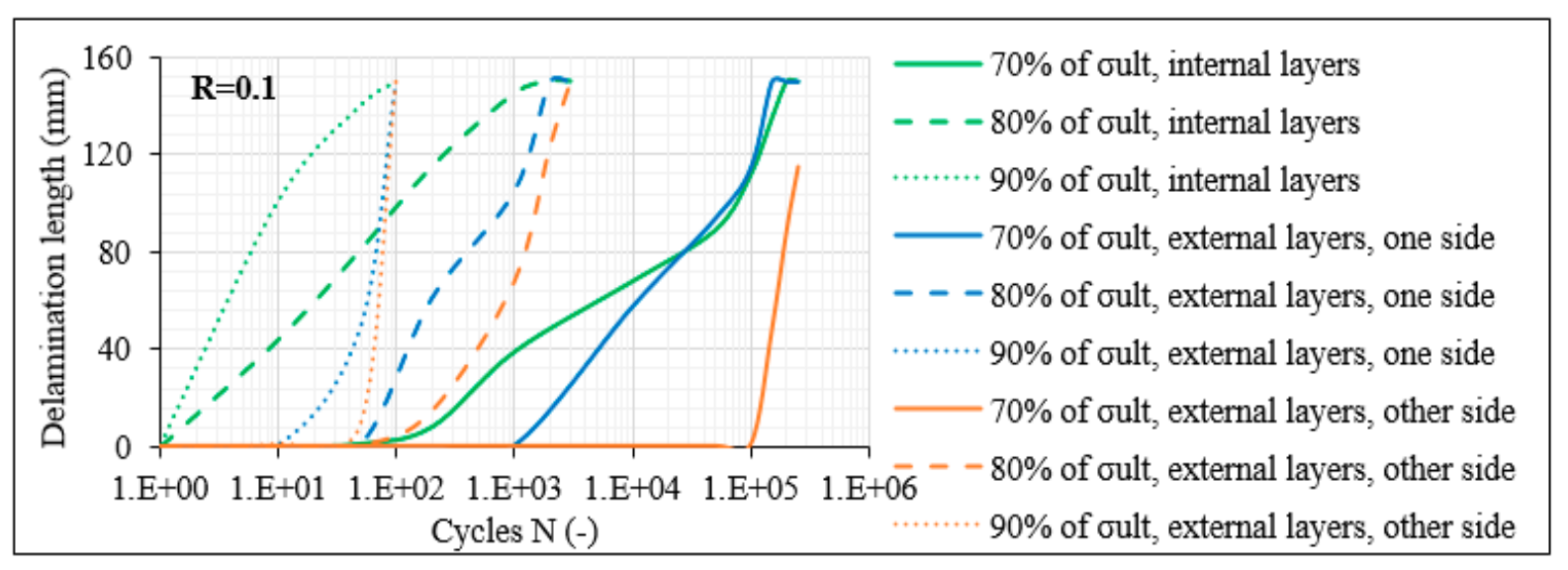

Figure 17. Delamination crack growth versus $\mathrm{N}$ in $\left[0^{\circ} / 30^{\circ} / 0^{\circ} /-30^{\circ}\right]_{\mathrm{S}}$ laminates for $\mathrm{R}=0.1$.

Regarding the $\left[0^{\circ} / 30^{\circ} /-30^{\circ}\right]_{2 s}$ laminates and the influence of the number of the off-axis layers on the fatigue response, unstable cracking phenomena were also in this case reported, such as in the 12 -ply $\left[0^{\circ} / 60^{\circ} /-60^{\circ}\right]_{2 \mathrm{~s}}$ laminates. In this case, the deterioration of different regions was observed during testing, without however leading to coupling of the local delaminations along the total length. This fracture mode was observed only in these laminates, since in all previous cases, cracking was more uniform, initiating at one locus and propagating along the total specimen length. It was characteristic that in many cases, a full deterioration of one region was suddenly observed, consisting of multiple matrix cracks and delaminations along a limited length of maximum $10 \mathrm{~mm}$. Due to the multiple interfaces along the laminate thickness, these fractured phenomena saturated almost immediately. Multiple fractured areas were observed along the laminate length as the test progressed, with a higher number when the maximum fatigue stress was increased. However, the fracture events in different laminate areas were independent for the longest time span of the test. As the test progressed, only the isolated outer-ply delaminations were finally connected, leading to a full-length propagation and final failure. Based on this description, the total deterioration of the 12-ply $\left[0^{\circ} / 30^{\circ} /-30^{\circ}\right]_{2 s}$ laminates was quite similar to that of the 8-ply $\left[0^{\circ} / 30^{\circ} / 0^{\circ} /-30^{\circ}\right]_{S}$ laminates for the same fatigue conditions, a trend that was confirmed also under static loading [40].

\subsubsection{Edge Damage Microscopic Monitoring}

To verify the previous discussion, characteristic microscopy images are shown in Figures 18-20 for the 8-ply unbalanced and the 8-ply and 12-ply balanced lay-ups, respectively. To depict the aforementioned differences regarding the fatigue damage of the laminates, it was chosen to exhibit their damage state for $\sigma_{\max }=0.8 \times \sigma_{\text {ult }}$ and $R=0.1$ after 50 and 200 cycles. All the findings obtained from the previous demonstration are supported by the microscopy images, which present both the qualitative and the quantitative damage state of the laminates. Delaminations are pronounced in the shear-dominated laminates and matrix cracking in the lay-ups with high $\sigma_{22}$ stresses. The positive response of the unbalanced laminates is revealed, and the impact of the number of the off-axis plies is verified from the beginning of the fatigue life. 

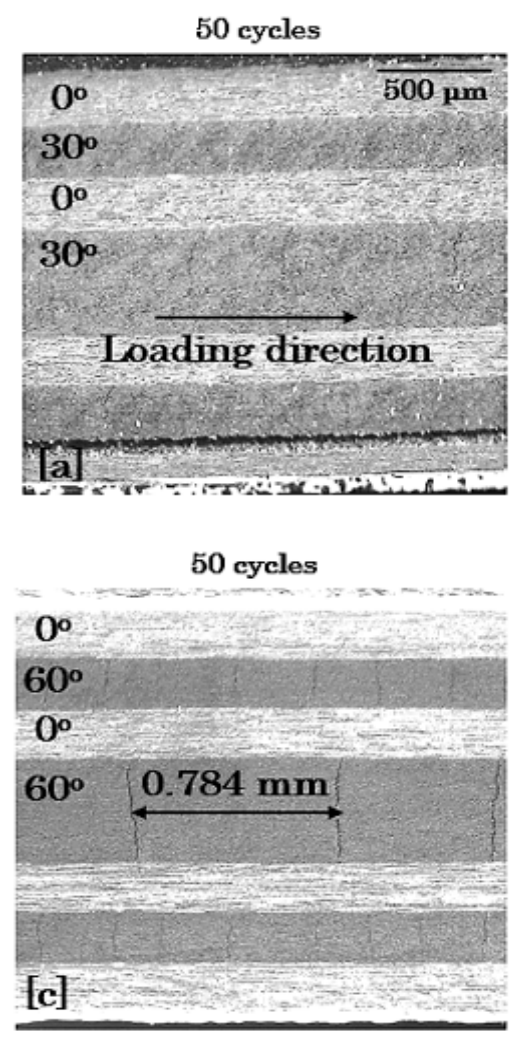
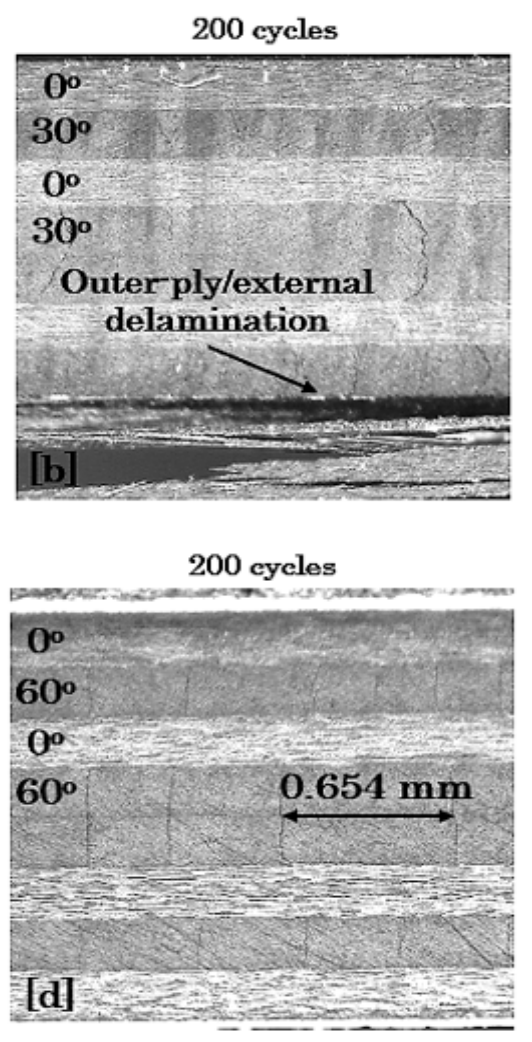

Figure 18. Damage in $\left[0^{\circ} / 30^{\circ}\right]_{2 s}$ (top) and $\left[0^{\circ} / 60^{\circ}\right]_{2 s}$ (bottom) laminates after (a,c) 50 and (b,d) 200 cycles for $\sigma_{\max }=0.8 \times \sigma_{\text {ult }}$ and $\mathrm{R}=0.1$.
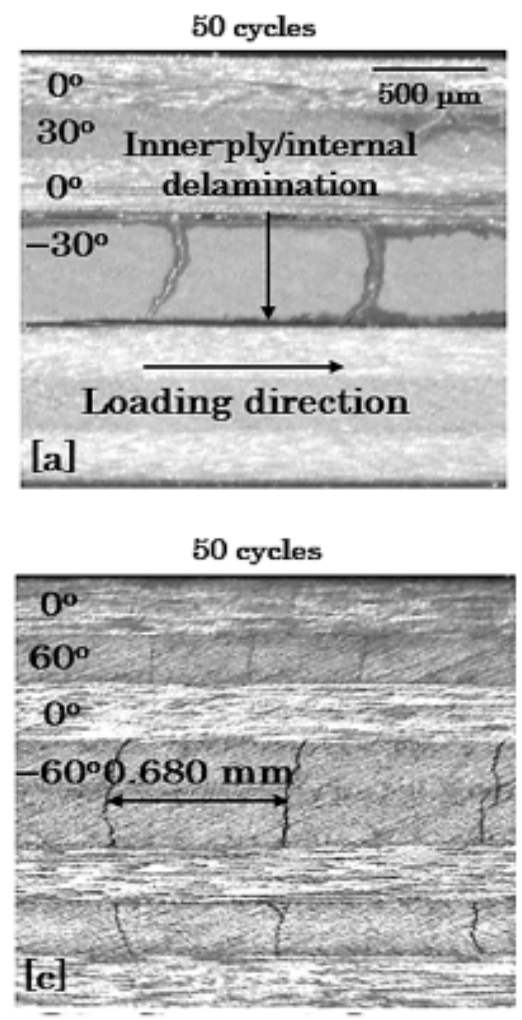

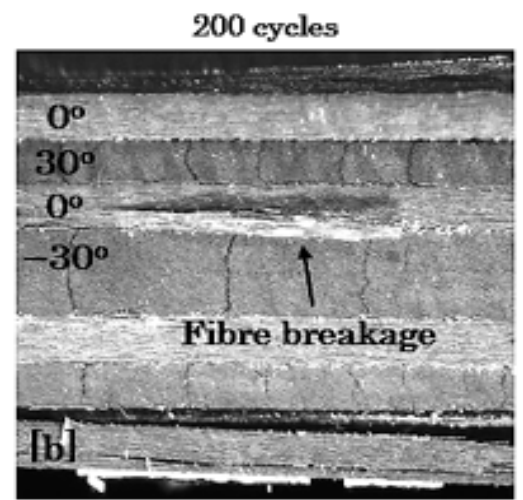

200 cycles

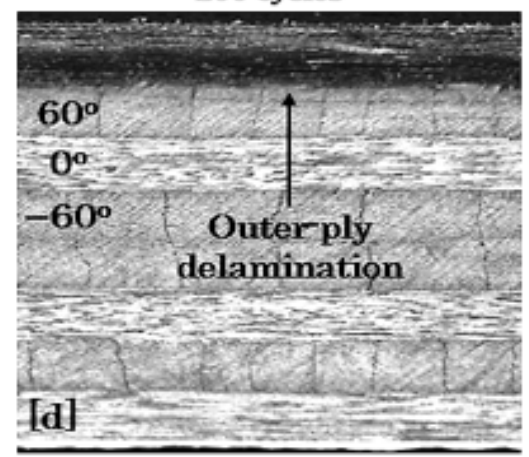

Figure 19. Damage in $\left[0^{\circ} / 30^{\circ} / 0^{\circ} /-30^{\circ}\right]_{\mathrm{s}}$ (top) and $\left[0^{\circ} / 60^{\circ} / 0^{\circ} /-60^{\circ}\right]_{\mathrm{s}}$ (bottom) laminates after $(\mathbf{a}, \mathbf{c}) 50$ and $(\mathbf{b}, \mathbf{d}) 200$ cycles for $\sigma_{\max }=0.8 \times \sigma_{\text {ult }}$ and $\mathrm{R}=0.1$. 


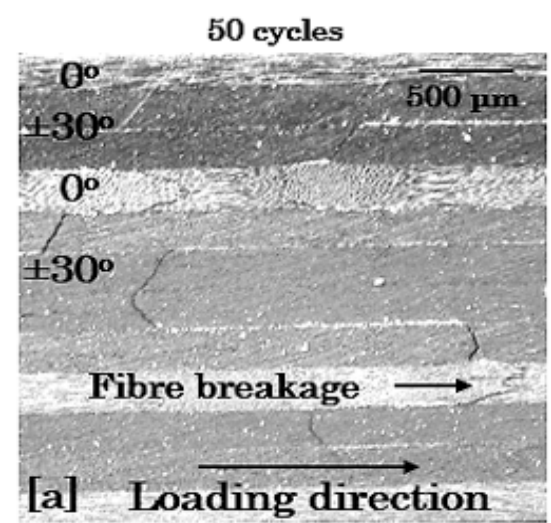

50 cycles

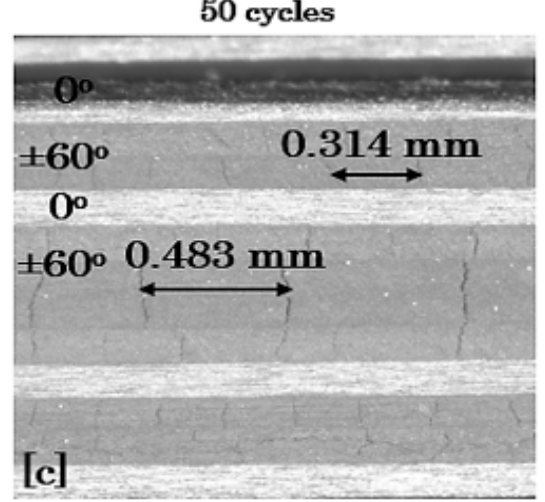

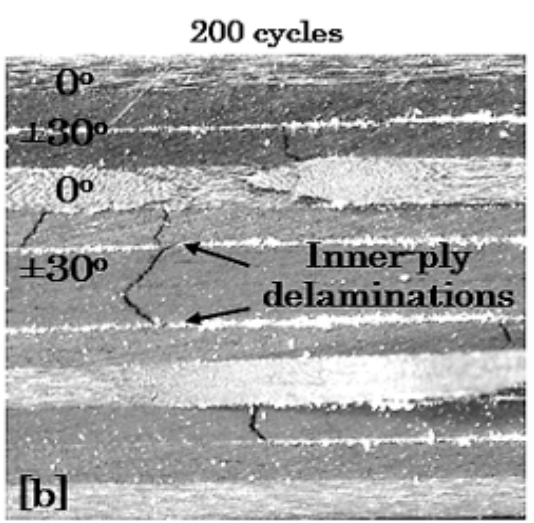

200 cycles

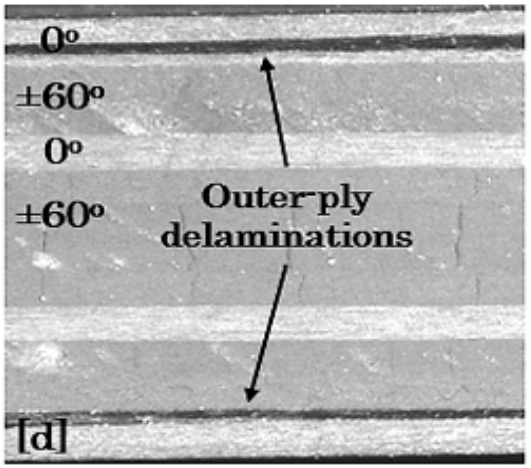

Figure 20. Damage in $\left[0^{\circ} / 30^{\circ} /-30^{\circ}\right]_{2 s}$ (top) and $\left[0^{\circ} / 60^{\circ} /-60^{\circ}\right]_{2 s}$ (bottom) laminates after (a,c) 50 and $(\mathbf{b}, \mathbf{d}) 200$ cycles for $\sigma_{\max }=0.8 \times \sigma_{\text {ult }}$ and $\mathrm{R}=0.1$.

The previously presented damage findings at the edge of the laminates were also confirmed by performing midplane damage monitoring. To do this, specimens were loaded until a certain number of fatigue cycles, and then, they were cut along their middle axis. After polishing, damage monitoring was performed. The impact of the considered parameters was validated, confirming that the discussed trends are not only driven by edge phenomena.

\subsection{Stiffness Degradation and Poisson's Ratio Measurements}

All previous findings concerning the impact of shear, the comparison between balanced and unbalanced lay-ups and the influence of the number of off-axis layers were verified during the study of the stiffness degradation of the CFRP material. In Figure 21a,b, the measured stiffness degradation $\mathrm{E} / \mathrm{E}_{0}$ (with $\mathrm{E}_{0}$ being the initial laminate stiffness) for representative $\left[0^{\circ} / 30^{\circ}\right]_{2 s}$ and $\left[0^{\circ} / 60^{\circ}\right]_{2 s}$ specimens is, respectively, plotted for $\mathrm{R}=0.1$ during the $70 \%, 80 \%$ and $90 \% \sigma_{\max }$ cases versus the normalised fatigue life $\mathrm{N} / \mathrm{N}_{\mathrm{f}}$. It is obvious that a reduction in the stiffness is obtained when $\sigma_{\max }$ increases in both cases. A significant drop in stiffness is recorded during the first fatigue cycles, being higher for increasing $\sigma_{\max }$ levels. However, an importantly higher stiffness degradation is recorded for the $\left[0^{\circ} / 30^{\circ}\right]_{2 s}$ samples during the fatigue tests. 


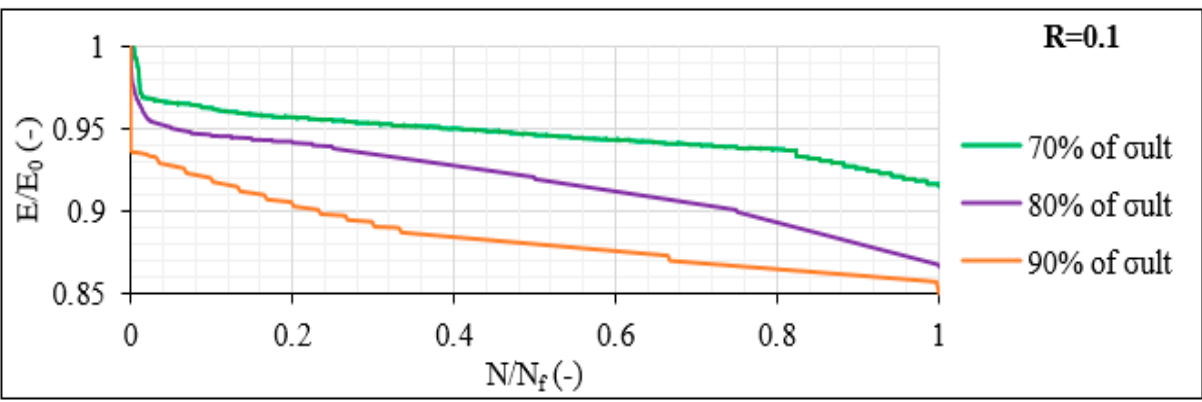

(a)

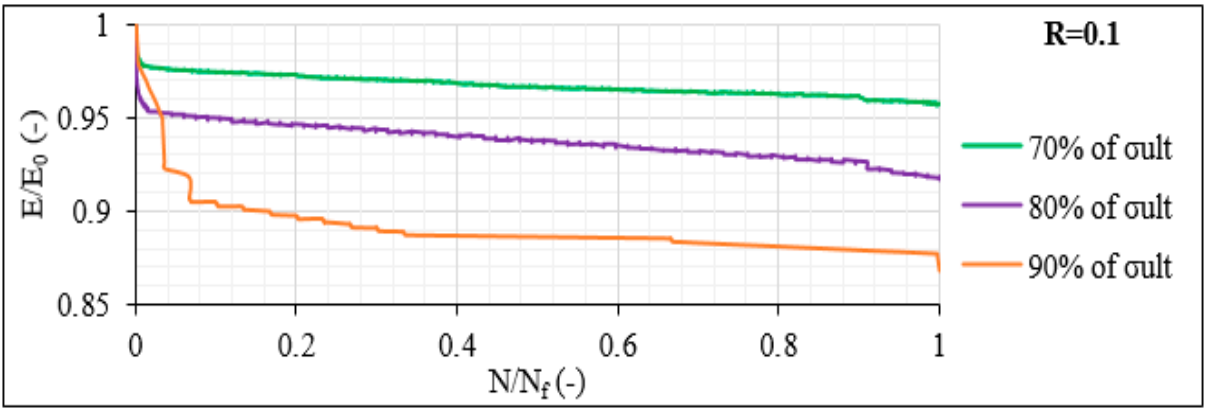

(b)

Figure 21. Stiffness degradation versus the normalised fatigue life in (a) $\left[0^{\circ} / 30^{\circ}\right]_{2 \mathrm{~s}}$ and (b) $\left[0^{\circ} / 60^{\circ}\right]_{2 \mathrm{~s}}$ laminates for $\mathrm{R}=0.1$.

To better display the impact of shear on the stiffness degradation as well as a comparison between the balanced and unbalanced laminates, in Figure 22a,b, the average $\mathrm{E}_{\mathrm{res}} / \mathrm{E}_{0}$ results (where $\mathrm{E}_{\mathrm{res}}$ is the residual stiffness of laminates that survived the run-out of one million cycles) for the 8-ply unbalanced and balanced laminates are, respectively, plotted. Shear seems to be in all cases detrimental. Matrix cracking in the transverse stressdominated laminates leads to a significant drop in stiffness during the initial fatigue cycles, with, however, reduced decreasing rates as the test proceeds despite the high matrix crack densities. When shear is dominant, the stiffness degradation continues with a higher rate owing to the shear stresses and the forming delaminations, reducing the fracture toughness and leading to severe deterioration. The balanced laminates follow similar trends with, however, higher stiffness drops at lower stress levels when compared to the unbalanced lay-ups for the same fatigue conditions.

After analysis of the Poisson's ratio $v_{x y}$ (in the geometrical coordinate system) during the fatigue tests, it was revealed that it has the potential to be used for damage indications during the loading of the CFRP material. In most cases, the Poisson's ratio had a decreasing trend over the total fatigue life, with that decrease always being higher for the more severe fatigue conditions, proving that the developing damage has an impact both on the longitudinal and the transverse strains, and therefore on $v_{x y}$. As an example, Figure 23 plots the $v_{x y}$ evolution versus the normalised fatigue life for one $\left[0^{\circ} / 30^{\circ}\right]_{2 \mathrm{~s}}$ specimen subjected to the $80 \%-0.5$ fatigue conditions and one specimen tested under $\sigma_{\max }=0.9 \times \sigma_{\text {ult }}$ and $\mathrm{R}=0.5$. The difference between the two samples lies in the fact that in the first case, the run-out of $10^{6}$ cycles was reached, while in the second case, the specimen failed after 425,693 cycles. In both cases, a continuous decrease in $v_{x y}$ is observed, although being lower in the case of the $80 \%-0.5$ test and proving the sensitivity of the Poisson's ratio to the developing damage in the material during the fatigue loading. 


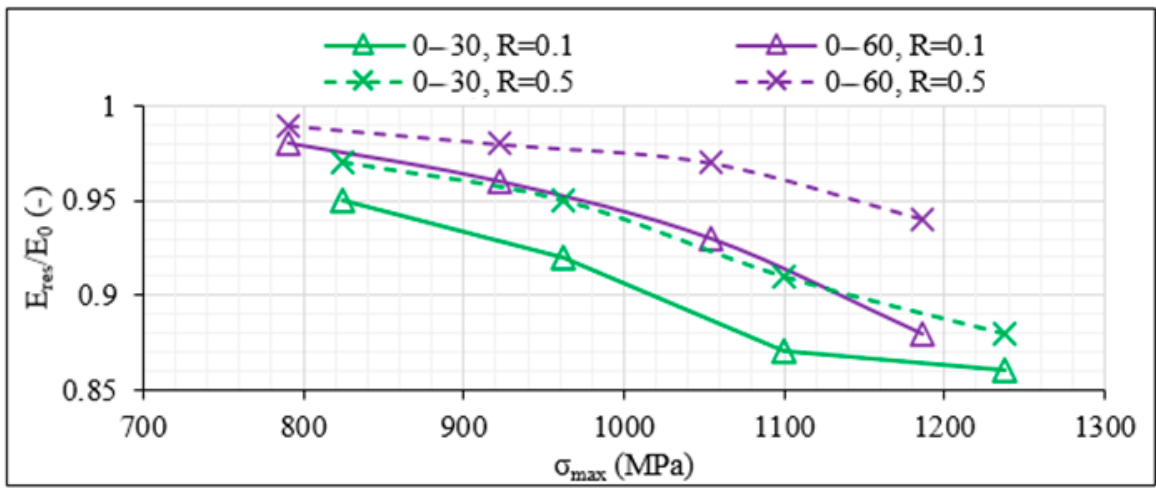

(a)

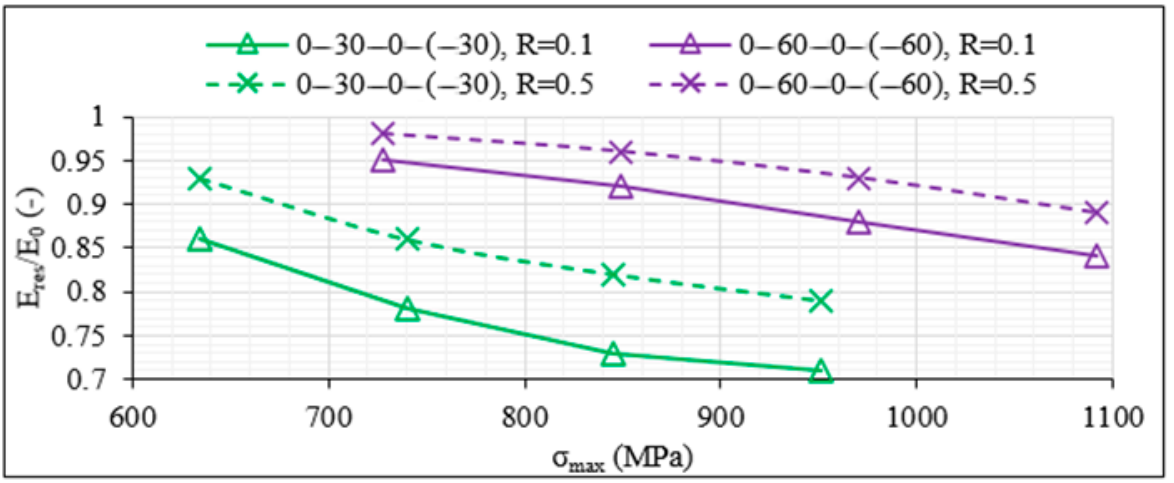

(b)

Figure 22. $E_{\text {res }} / E_{0}$ values versus $\sigma_{\max }$ obtained for $(\mathbf{a})\left[0^{\circ} / \theta\right]_{2 s}$ and $(\mathbf{b})\left[0^{\circ} / \theta / 0^{\circ} /-\theta\right]_{s}$ laminates.

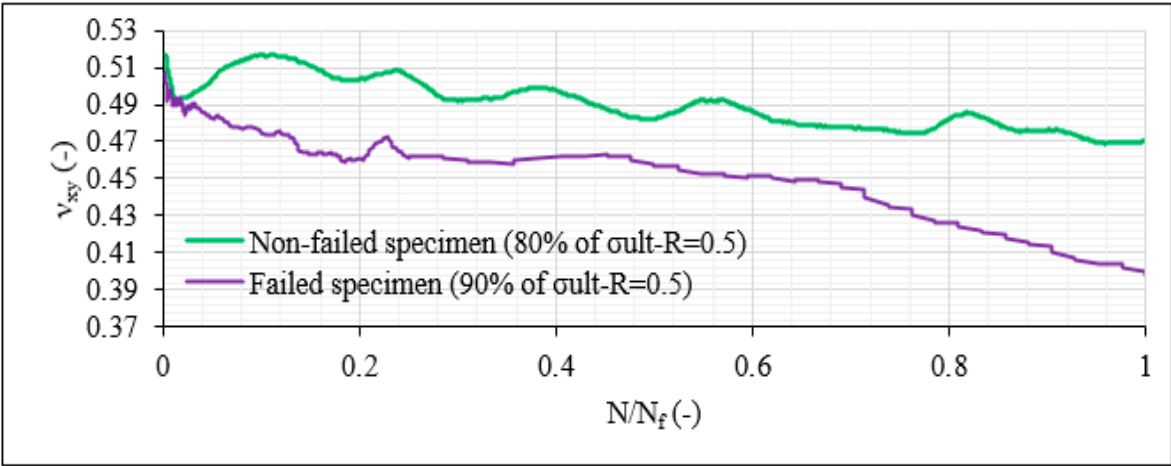

Figure 23. $v_{x y}$ evolution versus the normalised fatigue life for one nonfailed $\left[0^{\circ} / 30^{\circ}\right]_{2 s}$ laminate $\left(\sigma_{\max }=0.8 \times \sigma_{\mathrm{ult}}\right.$ and $\left.\mathrm{R}=0.5\right)$ and one failed $\left[0^{\circ} / 30^{\circ}\right]_{2 \mathrm{~s}}$ laminate $\left(\sigma_{\max }=0.9 \times \sigma_{\text {ult }}\right.$ and $\left.\mathrm{R}=0.5\right)$.

As a final point, it should be mentioned that, in particular, the balanced $\left[0^{\circ} / 30^{\circ} / 0^{\circ} /-30^{\circ}\right]_{\mathrm{s}}$ and $\left[0^{\circ} / 30^{\circ} /-30^{\circ}\right]_{2 \mathrm{~s}}$ laminates presented a very characteristic response that should be better demonstrated. In these laminates, during the initial fatigue stage, a very sudden stiffness drop was always monitored with a continuous decrease thereafter, whereas in the unbalanced laminates, a more gradual stiffness decrease was observed. It was noticed that the higher the applied load and therefore the amount of developing damage, the higher this stiffness drop was. Moreover, for higher stresses, this drop in stiffness occurred earlier during the fatigue life, corresponding to the higher damage extent. To demonstrate this behaviour, Figure 24a plots the stiffness degradation of one 8-ply balanced $\left[0^{\circ} / 30^{\circ} / 0^{\circ} /-30^{\circ}\right]_{\mathrm{s}}$ laminate during the $70 \%-0.1$ fatigue test. Contrary to the unbalanced laminates, a big drop in stiffness is suddenly observed during the initial fatigue cycles due to a rapid increase in the longitudinal $\varepsilon_{\mathrm{xx}}$ strains (in the direction of the loading), as shown in Figure $24 \mathrm{~b}$, plotting the $\varepsilon_{x x}$ evolution for the same test from the beginning until $5 \%$ of 
$\mathrm{N}_{\mathrm{f}}$. This response can be attributed to the generally higher deterioration of the balanced laminates, as already explained in the previous sections, with delaminations accompanied in all cases by fibre breakage. Another reason can be the faster propagation of the damage from the edge of the laminate toward the inner volume of the material, as confirmed by the mid-plane microscopic observations.

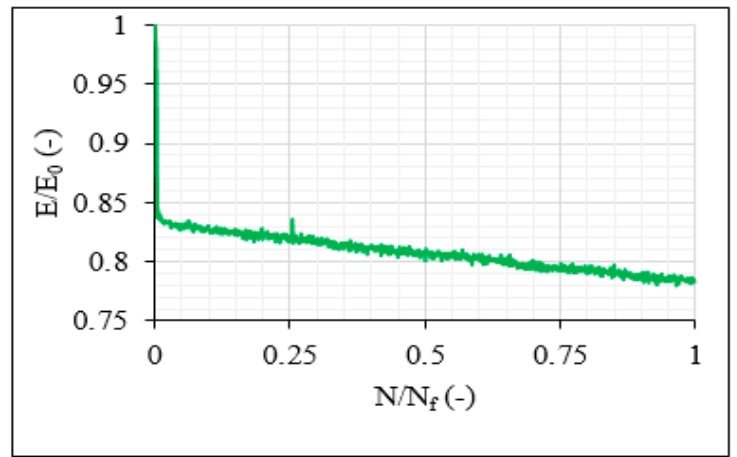

(a)

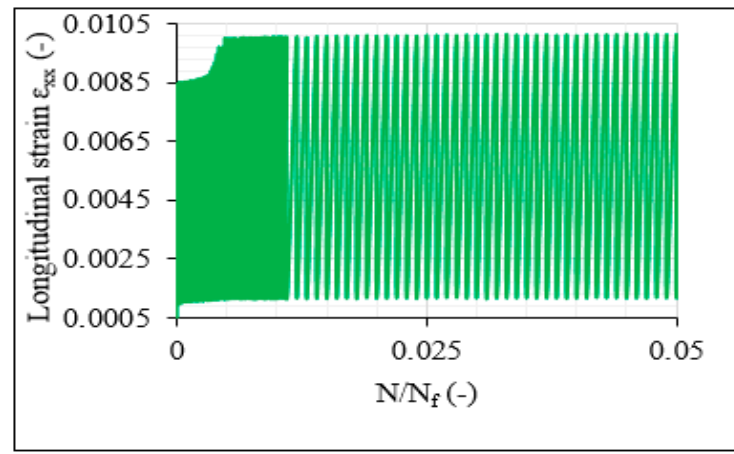

(b)

Figure 24. (a) Stiffness degradation versus the normalised fatigue life and (b) $\varepsilon_{\mathrm{xx}}$ evolution during the $0-0.05 \mathrm{~N} / \mathrm{N}_{\mathrm{f}}$ period for one $\left[0^{\circ} / 30^{\circ} / 0^{\circ} /-30^{\circ}\right]_{\mathrm{s}}$ laminate for the $70 \%-0.1$ test.

Following the observations regarding the stiffness degradation measurements, similar trends were also obtained for the Poisson's ratio in the balanced laminates. A characteristic example is presented in Figure 25a for the same balanced $\left[0^{\circ} / 30^{\circ} / 0^{\circ} /-30^{\circ}\right]_{\mathrm{s}}$ laminate tested under the 70\%-0.1 fatigue conditions. A decreasing trend is also in this case recorded with a significant drop after a certain amount of fatigue cycles. It was generally observed that in the more severe fatigue conditions, a higher drop of the Poisson's ratio occurred, appearing earlier during the fatigue life and being always accompanied by a more gradual decrease afterward. Specimens tested under lower stress levels and reaching a higher number of fatigue cycles were characterised by a small increasing tendency of $v_{x y}$ during the initial fatigue cycles, as shown in Figure 25a, followed later by a sudden drop, attributed to rapid increase in the longitudinal $\varepsilon_{x x}$ strains and decrease in the transverse $\varepsilon_{y y}$ strains due to the propagation of the damage toward the inner volume of the laminate. In Figure 25b, the evolution of the Poisson's ratio during the first $6 \times 10^{3}$ fatigue cycles is plotted for the same specimen to demonstrate the above description.

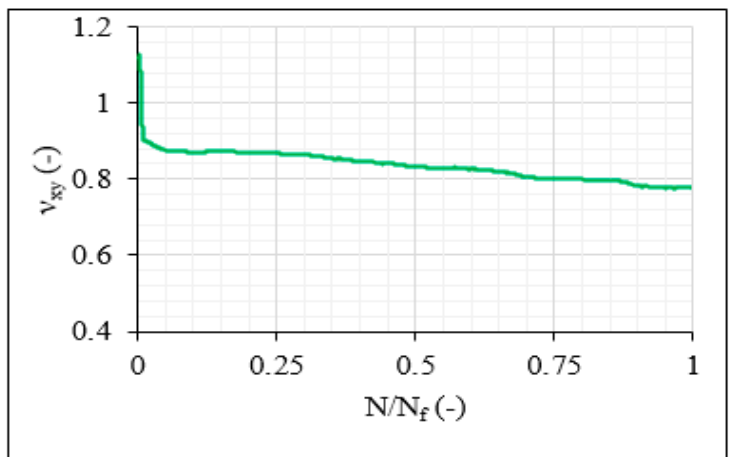

(a)

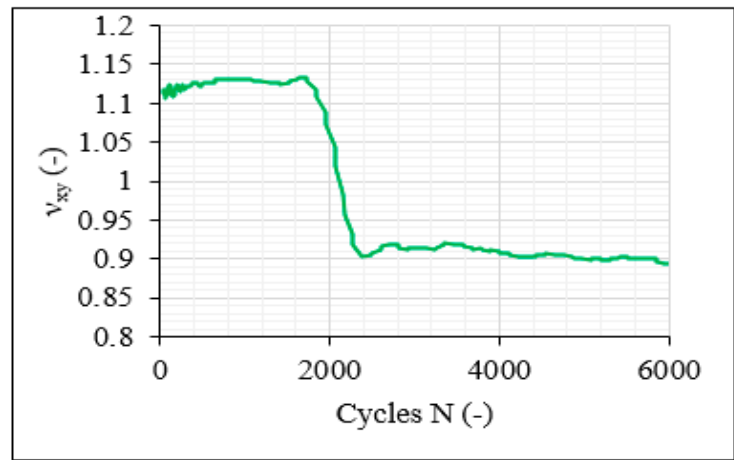

(b)

Figure 25. $v_{\mathrm{xy}}$ evolution (a) versus the normalised fatigue life and (b) during the first fatigue $6 \times 10^{3}$ cycles for one $\left[0^{\circ} / 30^{\circ} / 0^{\circ} /-30^{\circ}\right]_{s}$ laminate for the $70 \%-0.1$ test. 


\section{Conclusions and Observations}

- The effect of multiaxiality, a comparison between balanced and unbalanced composite laminates and the impact of the number of off-axis layers on the tension-tension fatigue response were demonstrated in this work by testing angle-ply CFRP $\left[0^{\circ} / \theta\right]_{2 \mathrm{~s}}$, $\left[0^{\circ} / \theta / 0^{\circ} /-\theta\right]_{s}$ and $\left[0^{\circ} / \theta /-\theta\right]_{2 s}$ laminates for two different off-axis angles, namely $30^{\circ}$ and $60^{\circ}$.

- The mechanical response was initially studied in terms of $\mathrm{S}-\mathrm{N}_{\mathrm{f}}$ and residual strength data. The impact of shear was clearly indicated with laminates consisting of $30^{\circ}$ off-axis plies leading to lower $\mathrm{N}_{\mathrm{f}}$ and residual strength values.

- A high impact of the R-ratio was also revealed. An R-ratio equal to 0.5, corresponding to lower stress amplitude during fatigue loading, resulted always in higher fatigue life.

- One of the most interesting findings concerns the response of the unbalanced laminates when compared with the balanced lay-ups. Both in terms of S- $\mathrm{N}_{\mathrm{f}}$ and residual strength data, a much better performance was observed for the first time for the unbalanced laminates having the same off-axis angle and being tested under the same fatigue conditions as the balanced ones.

- All findings were confirmed by studying the progressive damage accumulation during fatigue. In all cases, matrix cracking was the initial damage mode appearing, leading to the interlaminar delaminations and final fibre breakage in laminates that did not survive the run-out of one million cycles. Nevertheless, important uncoverings were obtained when the shear-dominated laminates were compared with the laminates in which the transverse stresses dominate the stress state.

- Specifically, for the laminates with $60^{\circ}$ off-axis plies, matrix cracks appeared in all offaxis layers during the very first fatigue cycles. Moreover, a saturation criterion applied, indicating that when the transverse stresses determine the damage accumulation, interlaminar delaminations during fatigue loading occur only after a certain saturation of the matrix cracks was reached.

- It was confirmed that the CDS was very similar both for the balanced and the unbalanced 8-ply laminates. However, it was reached quite earlier in the balanced lay-up, leading more quickly to the initiation and propagation of interlaminar delaminations for the same stress level.

- Significantly higher matrix crack densities were acquired though for the 12-ply laminates with an off-axis angle of $60^{\circ}$, showing a certain impact of the number of off-axis plies on the fatigue response.

- By contrast, the damage response was different in the shear-dominated laminates. In addition, in this case, matrix cracking was the initial damage mode appearing. However, initial matrix cracks only appeared in the middle thick layer in the 8-ply balanced and unbalanced lay-ups, and the onset of cracking was not consistently observed during the very first fatigue cycles. Only when the crack density reached a certain value in the middle thick layer, delaminations and matrix cracks in the thin off-axis layers initiated.

- The crack density limit, after which the delaminations started occurring in the laminate was quite smaller for the balanced laminates, indicating a significantly lower fracture toughness.

- The 12-ply shear-dominated laminates presented a somehow different damage response. In this case, the multiple interphases owing to the higher number of off-axis layers rapidly led to the local deterioration of the laminate at certain fractured areas. Nevertheless, the interphases acted also as obstacles for the development of damage along the total laminate length.

- The impact of the different parameters on the fatigue response was confirmed in all cases by applying both edge and midplane microscopy.

- Finally, stiffness degradation and Poisson's ratio measurements validated the response of the material under the different conditions. 
- Higher stiffness degradation was observed for increasing shear stresses and for the balanced lay-ups.

- The Poisson's ratio seemed to be a satisfactory qualitative damage indicator, maintaining reducing trends during fatigue and correlating promisingly with the extent of damage.

Author Contributions: Conceptualization, K.-A.K., D.V.H. and L.P; methodology, K.-A.K.; software, K.-A.K.; validation, K.-A.K.; formal analysis, K.-A.K.; investigation, K.-A.K.; resources, K.-A.K., D.V.H. and L.P.; data curation, K.-A.K.; writing—original draft preparation, K.-A.K.; writing-review and editing, K.-A.K., D.V.H. and L.P.; visualization, K.-A.K.; supervision, D.V.H. and L.P.; project administration, D.V.H. and L.P.; funding acquisition, D.V.H. and L.P. All authors have read and agreed to the published version of the manuscript.

Funding: The work leading to this publication was partially funded by the SBO project "M3Strength", which fits in the MacroModelMat (M3) research program, coordinated by Siemens (Siemens Digital Industries Software, Belgium) and funded by SIM (Strategic Initiative Materials in Flanders) and VLAIO (Flanders Innovation and Entrepreneurship Agency). The authors gratefully acknowledge the material suppliers Mitsubishi Chemical Corporation and Honda R\&D Co., Ltd. and would like to thank the financial support of the Fonds Wetenschappelijk Onderzoek (FWO) research program "Multi-scale modelling and characterisation of fatigue damage in unidirectionally reinforced polymer composites under multiaxial and variable-amplitude loading" (G.0090.15).

Data Availability Statement: Data sharing is not applicable to this article.

Conflicts of Interest: The authors declare no conflict of interest.

\section{References}

1. Quaresimin, M. 50th anniversary article: Multiaxial fatigue testing of composites: From the pioneers to future directions. Strain 2015, 51, 16-29. [CrossRef]

2. Hinton, M.; Kaddour, A.S.; Soden, P.D. Failure Criteria in Fibre Reinforced Polymer Composites: The World-Wide Failure Exercise, 1st ed.; Elsevier: Amsterdam, The Netherlands, 2004.

3. Takeda, N.; Ogihara, S.; Kobayashi, A. Microscopic fatigue damage progress in CFRP cross-ply laminates. Composites 1995, 26, 859-867. [CrossRef]

4. Kobayashi, S.; Takeda, N. Experimental and analytical characterization of transverse cracking behavior in carbon/bismaleimide cross-ply laminates under mechanical fatigue loading. Compos. Part B Eng. 2002, 33, 471-478. [CrossRef]

5. Berthelot, J.M. Transverse cracking and delamination in cross-ply glass-fiber and carbon-fiber reinforced plastic laminates: Static and fatigue loading. Appl. Mech. Rev. 2003, 56, 111-147. [CrossRef]

6. Bezazi, A.R.; El Mahi, A.; Berthelot, J.M.; Bezzazi, B. Flexural fatigue behavior of cross-ply laminates: An experimental approach. Strength Mater. 2003, 35, 149-161. [CrossRef]

7. Silberschmidt, V.V. Matrix cracking in cross-ply laminates: Effect of randomness. Compos. Part A Appl. Sci. Manuf. 2005, 36, 129-135. [CrossRef]

8. Van Paepegem, W.; De Baere, I.; Lamkanfi, E.; Degrieck, J. Monitoring quasi-static and cyclic fatigue damage in fibre-reinforced plastics by Poisson's ratio evolution. Int. J. Fatigue 2010, 32, 184-196. [CrossRef]

9. Al-Khudairi, O.; Hadavinia, H.; Waggott, A.; Lewis, E.; Little, C. Characterising mode I/mode II fatigue delamination growth in unidirectional fibre reinforced polymer laminates. Mater Des (1980-2015) 2015, 66, 93-102. [CrossRef]

10. Yao, L.; Sun, Y.; Guo, L.; Jia, L.; Zhao, M. A validation of a modified Paris relation for fatigue delamination growth in unidirectional composite laminates. Compos. Part B Eng. 2018, 132, 97-106. [CrossRef]

11. Kim, H.S.; Huang, S. S-N curve characterisation for composite materials and prediction of remaining fatigue life using damage function. J. Compos. Sci. 2021, 5, 76. [CrossRef]

12. Plumtree, A.; Melo, M.; Dahl, J. Damage evolution in a $[ \pm 45]_{2 \mathrm{~s}}$ CFRP laminate under block loading conditions. Int. J. Fatigue 2010, 32, 139-145. [CrossRef]

13. Movahedi-Rad, A.V.; Keller, T.; Vassilopoulos, A.P. Fatigue damage in angle-ply GFRP laminates under tension-tension fatigue. Int. J. Fatigue 2018, 109, 60-69. [CrossRef]

14. Reifsnider, K.L.; Talug, A. Analysis of fatigue damage in composite laminates. Int. J. Fatigue 1980, 2, 3-11. [CrossRef]

15. Ramakrishnan, V.; Jayaraman, N. Mechanistically based fatigue-damage evolution model for brittle matrix fibre-reinforced composites. J. Mater. Sci. 1993, 28, 5592-5602. [CrossRef]

16. Varvani-Farahani, A.; Shirazi, A. A fatigue damage model for (0/90) FRP composites based on stiffness degradation of 0 and 90 composite plies. J. Reinf. Plast. Comp. 2007, 26, 1319-1336. [CrossRef] 
17. Korkiakoski, S.; Brøndsted, P.; Sarlin, E.; Saarela, O. Influence of specimen type and reinforcement on measured tension-tension fatigue life of unidirectional GFRP laminates. Int. J. Fatigue 2016, 85, 114-129. [CrossRef]

18. Roundi, W.; El Mahi, A.; El Gharad, A.; Rebiere, J.L. Acoustic emission monitoring of damage progression in glass/epoxy composites during static and fatigue tensile tests. Appl. Acoust. 2018, 132, 124-134. [CrossRef]

19. Ye, L. On fatigue damage accumulation and material degradation in composite materials. Compos. Sci. Technol. 1989, 36, 339-350 [CrossRef]

20. Tserpes, K.I.; Papanikos, P.; Labeas, G.; Pantelakis, S. Fatigue damage accumulation and residual strength assessment of CFRP laminates. Compos. Struct. 2004, 63, 219-230. [CrossRef]

21. May, M.; Hallett, S.R. Damage initiation in polymer matrix composites under high-cycle fatigue loading-A question of definition or a material property? Int. J. Fatigue 2016, 87, 59-62. [CrossRef]

22. El Kadi, H.; Ellyin, F. Effect of stress ratio on the fatigue of unidirectional glass fibre/epoxy composite laminae. Composites 1994, 25, 917-924. [CrossRef]

23. Philippidis, T.P.; Vassilopoulos, A.P. Fatigue of composite laminates under off-axis loading. Int. J. Fatigue 1999, $21,253-262$. [CrossRef]

24. Kawai, M.; Suda, H. Effects of non-negative mean stress on the off-axis fatigue behavior of unidirectional carbon/epoxy composites at room temperature. J. Compos. Mater. 2004, 38, 833-854. [CrossRef]

25. Burhan, I.; Kim, H.S. S-N curve models for composite materials characterisation: An evaluative review. J. Compos. Sci. 2018, 2, 38. [CrossRef]

26. Böhm, M.; Głowacka, K. Fatigue life estimation with mean stress effect compensation for lightweight structures-The case of GLARE 2 composite. Polymers 2020, 12, 251. [CrossRef] [PubMed]

27. May, M.; Pullin, R.; Eaton, M.; Featherston, C.; Hallett, S.R. An advanced model for initiation and propagation of damage under fatigue loading-Part II: Matrix cracking validation cases. Compos. Struct. 2011, 93, 2350-2357. [CrossRef]

28. Quaresimin, M.; Carraro, P.A.; Mikkelsen, L.P.; Lucato, N.; Vivian, L.; Brøndsted, P.; Sørensen, B.F.; Varna, J.; Talreja, R. Reprint of: Damage evolution under cyclic multiaxial stress state: A comparative analysis between glass/epoxy laminates and tubes. Compos. Part B Eng. 2014, 65, 2-10. [CrossRef]

29. Liu, D. Impact-induced delamination-A view of bending stiffness mismatching. J. Compos. Mater. 1988, 22, 674-692. [CrossRef]

30. Ho, K.C.; Hwang, J.R.; Doong, J.L. Impact fatigue of short glass fiber reinforced polycarbonate. J. Reinf. Plast. Comp. 1997, 16, 903-925. [CrossRef]

31. Baucom, J.N.; Zikry, M.A.; Rajendran, A.M. Low-velocity impact damage accumulation in woven S2-glass composite systems. Compos. Sci. Technol. 2006, 66, 1229-1238. [CrossRef]

32. Azouaoui, K.; Azari, Z.; Pluvinage, G. Evaluation of impact fatigue damage in glass/epoxy composite laminate. Int. J. Fatigue 2010, 32, 443-452. [CrossRef]

33. Lee, C.S.; Hwang, W.; Park, H.C.; Han, K.S. Failure of carbon/epoxy composite tubes under combined axial and torsional loading 1. Experimental results and prediction of biaxial strength by the use of neural networks. Compos. Sci. Technol. 1999, 59, 1779-1788. [CrossRef]

34. Qi, D.; Cheng, G. Fatigue behavior of filament-wound glass fiber reinforced epoxy composite tubes under tension/torsion biaxial loading. Polym. Compos. 2007, 28, 116-123. [CrossRef]

35. Quaresimin, M.; Carraro, P.A. Damage initiation and evolution in glass/epoxy tubes subjected to combined tension-torsion fatigue loading. Int. J. Fatigue 2014, 63, 25-35. [CrossRef]

36. Susuki, I. Fatigue damage of composite laminate under biaxial loads. In Mechanical Behaviour of Materials VI; Elsevier: Amsterdam, The Netherlands, 1992; pp. 543-548.

37. Makris, A.; Ramault, C.; Van Hemelrijck, D.; Zarouchas, D.; Lamkanfi, E.; Van Paepegem, W. An investigation of the mechanical behavior of carbon epoxy cross ply cruciform specimens under biaxial loading. Polym. Compos. 2010, 31, 1554-1561. [CrossRef]

38. Satapathy, M.R.; Vinayak, B.G.; Jayaprakash, K.; Naik, N.K. Fatigue behavior of laminated composites with a circular hole under in-plane multiaxial loading. Mater. Des. 2013, 51, 347-356. [CrossRef]

39. Quaresimin, M.; Carraro, P.A. On the investigation of the biaxial fatigue behaviour of unidirectional composites. Compos. Part $B$ Eng. 2013, 54, 200-208. [CrossRef]

40. Kalteremidou, K.A.; Hajikazemi, M.; Van Paepegem, W.; Van Hemelrijck, D.; Pyl, L. Effect of multiaxiality, stacking sequence and number of off-axis layers on the mechanical response and damage sequence of carbon/epoxy composite laminates under static loading. Compos. Sci. Technol. 2020, 190, 108044. [CrossRef]

41. ASTM. D3039, Standard Test Method for Tensile Properties of Polymer Matrix Composite Materials; ASTM: West Conshohocken, PA, USA, 2008. 